\title{
Searching for the Secret of Stickiness: How Biofilms Adhere to Surfaces
}

\author{
Zhaowei Jiang', Thomas Nero', Sampriti Mukherjee ${ }^{2}$, Rich Olson ${ }^{3}$ and Jing Yan ${ }^{1,4 *}$ \\ 'Department of Molecular, Cellular and Developmental Biology, Yale University, New Haven, CT, United States, ${ }^{2}$ Department \\ of Molecular Genetics and Cell Biology, University of Chicago, Chicago, IL, United States, ${ }^{3}$ Department of Molecular Biology \\ and Biochemistry, Molecular Biophysics Program, Wesleyan University, Middletown, CT, United States, ${ }^{4}$ Quantitative Biology \\ Institute, Yale University, New Haven, CT, United States
}

Bacterial biofilms are communities of cells enclosed in an extracellular polymeric matrix in which cells adhere to each other and to foreign surfaces. The development of a biofilm is a dynamic process that involves multiple steps, including cell-surface attachment, matrix production, and population expansion. Increasing evidence indicates that biofilm adhesion is one of the main factors contributing to biofilm-associated infections in clinics and biofouling in industrial settings. This review focuses on describing biofilm adhesion

OPEN ACCESS

Edited by:

Ilana Kolodkin-Gal, Weizmann Institute of Science, Israel

Reviewed by: Chien-Yi Chang, Newcastle University, United Kingdom

Joon-Hee Lee, Pusan National University, South Korea

*Correspondence: Jing Yan jing.yan@yale.edu

Specialty section: This article was submitted to Microbial Physiology and Metabolism, a section of the journal Frontiers in Microbiology

Received: 29 March 2021 Accepted: 28 May 2021 Published: 08 July 2021

Citation:

Jiang Z, Nero T, Mukherjee $S$, Olson $R$ and Yan J (2021) Searching for the Secret of Stickiness: How Biofilms Adhere to Surfaces. Front. Microbiol. 12:686793. doi: 10.3389/fmicb.2021.686793 strategies among different bacteria, including Vibrio cholerae, Pseudomonas aeruginosa, and Staphylococcus aureus. Techniques used to characterize biofilm adhesion are also reviewed. An understanding of biofilm adhesion strategies can guide the development of novel approaches to inhibit or manipulate biofilm adhesion and growth.

Keywords: adhesion, bacteria, biofilm, extracellular matrix, biomechanics, infection, pathogenesis

\section{INTRODUCTION}

Having lived on Earth for billions of years, bacteria thrive in hospitable environments, including rivers, soil, and vegetation, and further inhabit extreme environments, such as hot springs, the deep ocean, and even nuclear waste (Fredrickson et al., 2004; Fouke, 2016; Tarn et al., 2016). Bacteria in natural environments often survive in matrix-encased communities called biofilms (Hall-Stoodley et al., 2004; de la Fuente-Núñez et al., 2013). The biofilm matrix is made of extracellular polymeric substances (EPSs), which are a complex mixture consisting of exopolysaccharides, accessory proteins, lipids, and sometimes extracellular DNA (eDNA; Flemming et al., 2007). The EPS matrix enhances the adaptability and survival of bacteria in their natural niches, especially in harsh environments (Flemming and Wingender, 2010). Compared to their planktonic counterparts, matrix-embedded bacteria enjoy many evolutionary advantages (Dragoš and Kovács, 2017). For example, biofilm-dwelling cells are less susceptible to antibiotic treatment, harder to kill by the host immune system, and more resistant to mechanical forces once they attach firmly to surfaces (Stewart and Costerton, 2001; Lecuyer et al., 2011; Yan and Bassler, 2019).

The study of bacterial biofilms is highly relevant to human health. Many chronic and acute diseases, including cystic fibrosis (Moreau-Marquis et al., 2008), tuberculosis, and even dental gingivitis (Mark Welch et al., 2016), involve biofilm formation. Additionally, biofilms can survive and grow on fomites, including medical devices and implants (Levering et al., 2014), 
leading to nosocomial infections and widespread community transmission (Yamamoto et al., 2010). Indeed, biofilm-mediated infections exhibit a positive correlation with the development of chronic infectious diseases (Gómez and Prince, 2007; Bjarnsholt et al., 2008). On the other hand, biofilms can also be beneficial; examples include the biofilm sludge essential for wastewater treatment (Wuertz et al., 2003), plant root biofilms for nitrogen fixation (Poole, 2017), and beneficial commensal biofilms in the human gut (de Vos, 2015). Therefore, gaining a comprehensive understanding of how biofilms develop and adhere to surfaces would facilitate the screening of molecules to interfere with surface adhesion, leading to new treatments for biofilm-impacted diseases and potentially to new biofilm-based, functional materials (Huang et al., 2019).

The biofilm developmental cycle begins with planktonic cells approaching and subsequently attaching to a solid substrate (Hall-Stoodley et al., 2004). Many factors, including temperature, surface chemistry, the availability of nutrients, and fluid flow, can modulate the mechanism and strength of bacterial adhesion to surfaces (Bos et al., 1999). After settling, the surface-attached cells can move along the surface, aggregate, and start to build a three-dimensional (3D) structure through proliferation and EPS production. The EPS matrix further assists bacterial adhesion to diverse surfaces via divergent mechanisms depending on the species. When biofilm cells face environmental challenges, such as nutrient limitation, they undergo collective dispersal and reinitiate the biofilm developmental cycle on a new favorable surface (Rumbaugh and Sauer, 2020).

Although intuitive, the concept of biofilm adhesion is surprisingly difficult to define precisely. Unlike animals, such as squid that can rely on suction, or geckos that make use of a complex patterned surface topography (Autumn et al., 2014), biofilm-dwelling bacteria only have microscopic interactions to work with. These may include the binding of specific ligands or nonspecific interactions, such as van der Waals and hydrophobic interactions (Carniello et al., 2018). Physically, we can define adhesion as the force required to separate a biofilm from the underlying substrate. The molecular mechanisms underlying biofilm adhesion, however, can be complicated and species dependent. It is also difficult to draw a clear-cut line between the adhesion of individual bacterial cells and the adhesion of the entire biofilm, which may contain additional contributions from EPS, eDNA, and adhesion proteins, to foreign surfaces. Some biofilm-forming species possess specific adhesins that only function in the biofilm context, while other species use the same molecules for adhesion of both individual cells and biofilmdwelling cells. Interestingly, there is an inherent "avidity" effect (Erlendsson and Teilum, 2021) for biofilm adhesion: Adhesion molecules in the biofilm matrix can bind to foreign surfaces simultaneously and increase the adhesive energy collectively; meanwhile, adhesins that function for individual cells can be amplified on the scale of the entire biofilm. We therefore include both cases in the current review with a focus on adhesion molecules that are known to be relevant for biofilm formation; readers are referred to more comprehensive reviews on wellstudied adhesins that function primarily for isolated cells, such as FimH in Escherichia coli (Le Trong et al., 2010; Juge, 2012).
We start by reviewing current technologies to study biofilm adhesion and subsequently move on to various adhesion strategies adopted by several pathogenic bacteria with direct relevance to human health. We choose two Gram-negative species, Vibrio cholerae and Pseudomonas aeruginosa, and one Gram-positive species, Staphylococcus aureus, as illustrative examples. Finally, we propose some potential avenues for future research.

\section{TECHNIQUES USED TO CHARACTERIZE BIOFILM ADHESION}

A range of techniques have been established to study the adhesion of biofilms formed under both static and dynamic conditions. Biofilm adhesion can be either measured at the macroscopic or microscopic levels; Figure 1 gives a summary of existing techniques. At the macroscopic level, bulk rheology, a common technique to measure the mechanical properties of materials that possess both solid and liquid features, can be applied to quantify the viscoelasticity and adhesion of biofilms (Figure 1A). In general, biofilms can be conceptualized as porous, soft viscoelastic materials similar to hydrogels (Wloka et al., 2004); a shear rheometer is commonly employed for this purpose. When implemented in the tack test or lifting mode, a rheometer can be used to measure biofilm adhesion (Figures 2A,B). In this mode, the probe of the rheometer is lifted vertically, and the total energy needed to detach the biofilm from the probe is measured. For example, Gloag et al. adopted this method to measure the adhesive properties of biofilms formed by mucoid clinic isolates of P. aeruginosa (Gloag et al., 2018). By comparing pathoadapted $P$. aeruginosa variants to their isogenic wild-type (WT) parent, Gloag et al. demonstrated that mucoid colony biofilms are more cohesive compared to WT, whereas the adhesion of colony biofilms from WT and rugose small-colony variants are comparable (Figure 2C; Gloag et al., 2018). Coupling these results with other viscoelasticity measurements, they propose that biofilm mechanics should be considered as an important virulence property of biofilms. The drawback of using a rheometer for adhesion quantification is that other energy dissipation processes, such as biofilm deformation and fracturing, are involved and can even dominate during the measurement, resulting in a significant overestimation of the biofilm adhesion energy.

Another interesting macroscopic measurement is presented by Ohashi and Harada (1994; Figure 1B). They estimated the force required for biofilm detachment by imposing differential centrifugation forces on biofilms attached to a plate. The centrifugal force applied to the biofilm-attached plate can be converted into the biofilm adhesive force. However, the output data from this measurement are difficult to interpret since it is unclear whether fracture happens within the biofilm or at the biofilm-plate interface, and there are variations depending on the mode of centrifugation (Boudarel et al., 2018).

A straightforward and more popular method to measure bulk biofilm adhesion is the scratch test (Figure 1C; Chen et al., 1998). In brief, modifications are made to a micromanipulation device to include a $\mathrm{T}$-shaped blade connected to a force transducer. 


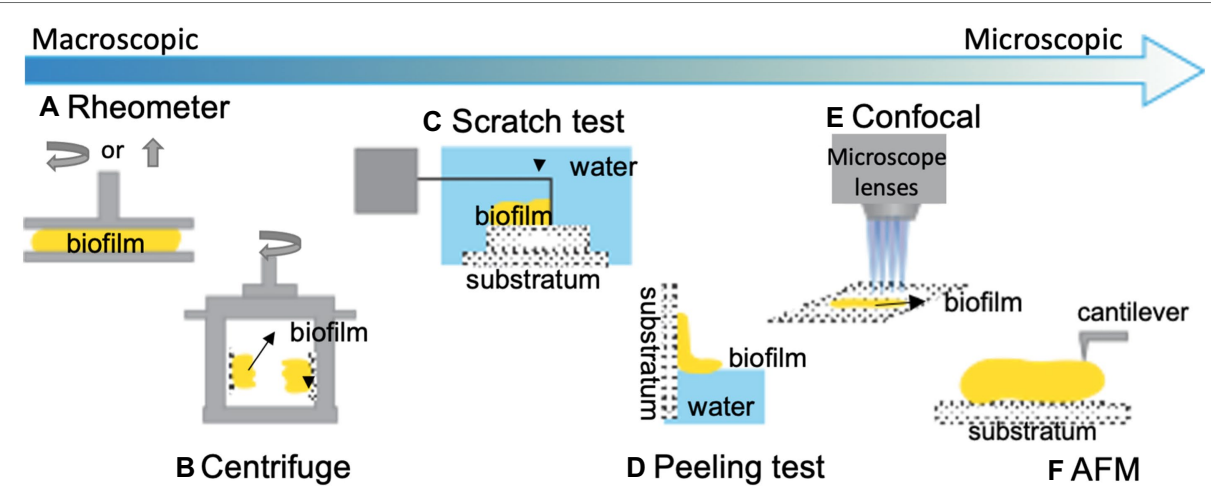

FIGURE 1 | Illustration of some common techniques for quantifying biofilm adhesion. (A) A shear rheometer is used to determine the viscoelastic and adhesive properties of bulk biofilms with different operating modes (Gloag et al., 2018). Yellow represents biofilm. (B) A centrifugal force is applied to biofilm-colonized plates installed on rotary tables to evaluate the biofilm adhesive strength (Ohashi and Harada, 1994). (C) A T-shaped blade is used to scratch biofilms off a surface to measure the energy required to detach a biofilm from the substratum (Chen et al., 1998). (D) A capillary force is used to peel hydrophobic biofilms off of hydrophilic substrates and measure the strength of the biofilm-substrate interaction (Yan et al., 2018). (E) Additionally, confocal-based techniques and (F) AFM-based techniques are commonly utilized for quantifying biofilm adhesion at the cellular scale. This figure is modified with permission from Boudarel et al. (2018).
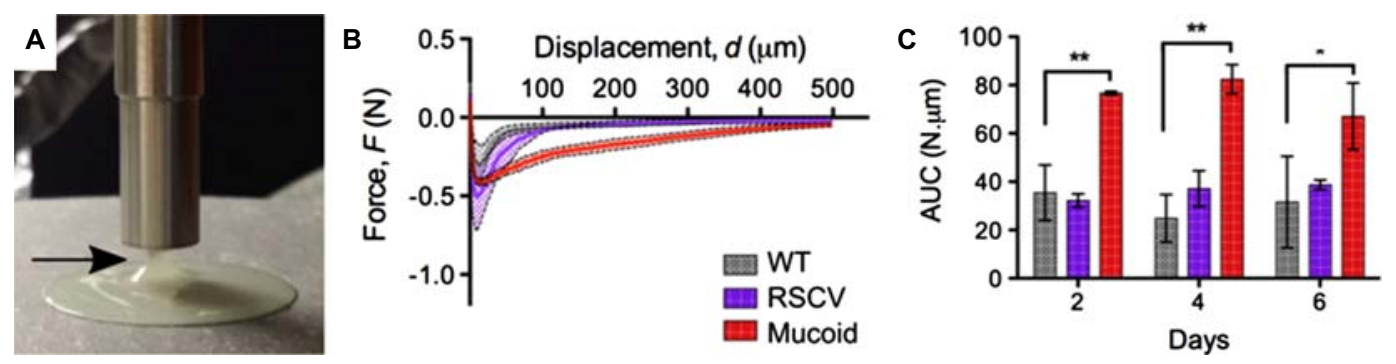

FIGURE 2 | Measurement of biofilm adhesion with a rheometer. (A) Image of a mucoid $P$. aeruginosa colony biofilm taken as the shaft of the rheometer is pulled away from the biofilm. The arrow indicates the biofilm adhered to the probe as it is raised off the biofilm. (B) Force-displacement curves of 4 -day-old $P$. aeruginosa colony biofilms from the unloading phase of the measurements. RSCV stands for rugose small colony variant. (C) Area under the curve (AUC) as a quantification of biofilm adhesion for 2-day-, 4-day-, and 6-day-old $P$. aeruginosa colony biofilms from measurements shown in (B). Data presented as mean \pm standard deviation (SD), $n=4$. * $p<0.01 ;{ }^{* *} p<0.001$. This figure is adapted with permission from Gloag et al. (2018).

During the scratch test, the T-shaped probe scrapes the biofilm horizontally off from the surface; the measured forces are subsequently calibrated with respect to a naïe surface. The biofilm adhesive strength can thus be defined as the work required to remove the biofilm per unit area (Chen et al., 1998). A typical value of $0.05 \sim 0.2 \mathrm{~J} / \mathrm{m}^{2}$ was reported for Pseudomonas fluorescens biofilms, which represents one of the first quantitative measurements of biofilm adhesive strength. Later, this method was adopted by Levering et al. to measure the adhesive strength between mixed community biofilms and the inner luminal surface of urinary catheters (Levering et al., 2016). This technique provides a straightforward and repeatable measurement of biofilm adhesive strength. However, the measurement is complicated by the elastic deformation of the biofilm being scraped off of the substrate, again leading to an overestimation of the biofilm adhesive strength.

More recently, a capillary-peeling-based technique was developed to measure the adhesive strength of colony biofilms grown at the air-solid interface (Figure 1D; Yan et al., 2018). By slowly dipping a biofilm grown on an agar plate into water, the biofilm is peeled off by capillary forces (Figure $\mathbf{3 A}$ ).
At the water-biofilm-agar triple contact point, a characteristic angle emerges at the equilibrium condition. This angle is determined by the adhesive energy between the biofilm and the substrate (Figure 3B). Interestingly, a slower dipping velocity leads to a higher success rate for peeling (Figure 3C), confirming the quasi-equilibrium nature of the peeling process. The measured value of $\sim 5 \mathrm{~mJ} / \mathrm{m}^{2}$ for $V$. cholerae colony biofilms is much smaller than that reported by other methods, which is believed to represent the inherent interfacial energy between these biofilms and their substrates. Moreover, the authors showed that the peeled biofilms can be transferred intact onto another substrate, therefore enabling high-resolution imaging and potentially other biofilm-related technologies. This method is unfortunately not applicable to hydrophilic biofilms, which do not peel off.

At the microscale level, there are two types of adhesion measurements: measurements that count the amount of surface-attached biomass and measurements that determine critical forces needed for cell detachment. The former technique relies heavily on imaging and is performed by a fluorescent microscope [most commonly a scanning confocal laser 

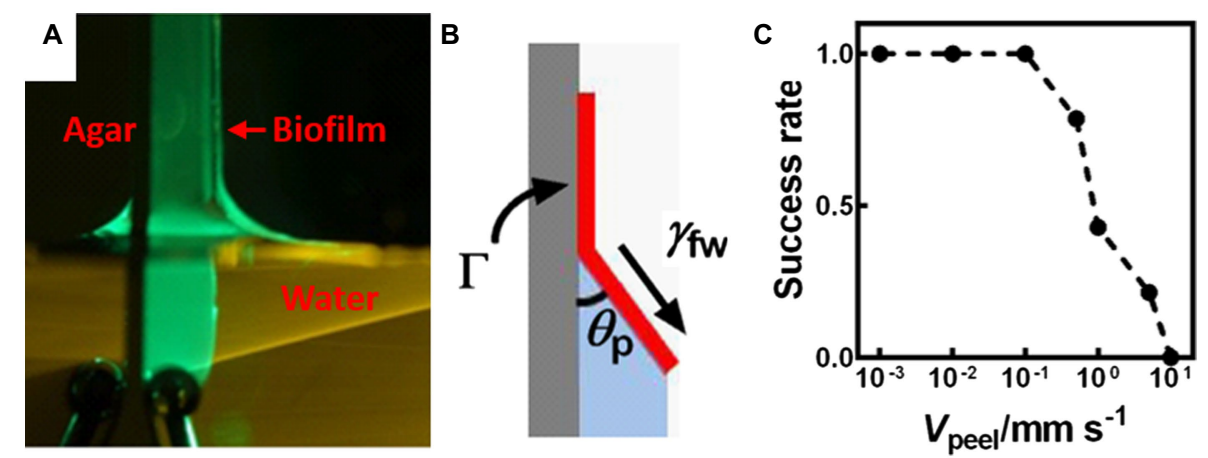

FIGURE 3 | Measurement of the adhesion energy between a biofilm and a substrate using capillary peeling. (A) Representative image of the capillary peeling process. A V. cholerae colony biofilm was first grown on an agar surface. The biofilm and the agar surface were gradually dipped into water, during which the biofilm is peeled off. (B) Schematic representation of the capillary peeling process. The interfacial tension $\left(\gamma_{\mathrm{fw}}\right)$ between the water and the biofilm causes peeling of the biofilm from the substrate with a constant peeling angle $\left(\theta_{p}\right) . \Gamma$ denotes the adhesion energy (energy/area) between the biofilm and the substrate. (C) The success rate of capillary peeling decreases with peeling velocity $\left(V_{\text {peel }}\right)$, suggesting that capillary peeling relies on equilibrium conditions rather than kinetics. This figure is reproduced with permission from Yan et al. (2018).

microscope (SCLM; Figure 1E)]. By quantifying and comparing the total biomass on the surface before and after some perturbation, a qualitative measure of adhesive strength can be obtained. This procedure is straightforward and allows a comparison between different strains or mutants, but it is qualitative in nature and therefore commonly used in combination with critical force measurements.

The method of critical force measurement allows a quantitative understanding of the adhesive strength of microbial communities. One commonly adopted technique is atomic force microscopy (AFM; Figure 1F) or single-cell force spectroscopy (SCFS; Binnig et al., 1986; Dufrene, 2002; Helenius et al., 2008). In AFM measurements, a sharp tip or cantilever scans over a surface (Gerber and Lang, 2006). At a particular location, a force-distance curve can be generated as the cantilever approaches a cell. The cantilever can be modified with different chemicals to represent different surfaces to which cells attach. As a result, a force-distance curve can be generated that carries quantitative information on the cell-to-substratum interaction (Fang et al., 2000). AFM can provide both a high-resolution image and quantitative force measurements, and therefore, it is a powerful tool for investigating the biofilm adhesion mechanism, especially when combined with mutagenesis, biochemistry, and single-cell visualization. Having reviewed the methodology involved in measuring biofilm adhesion, we now examine several model organisms to illustrate various strategies used by bacterial biofilms to attach to surfaces.

\section{GRAM-NEGATIVE SPECIES - VIBRIO CHOLERAE}

Vibrio cholerae is the causative agent of pandemic cholera (Nelson et al., 2009; Charles and Ryan, 2011). V. cholerae cells often attach to a surface in the aquatic environment and in host intestines, which suggests that surface adhesion is an important strategy for colonization during infections and is essential for survival in natural niches (Taylor et al., 1987; Huq et al., 1996; Kirn et al., 2005; Stauder et al., 2010; Purdy and Watnick, 2011). Biofilm formation has been suggested to enhance the survival of $V$. cholerae in the aquatic ecosystem and provides protection against the acidic stomach environment in the human host (Miller et al., 1984; Alam et al., 2007; Huq et al., 2008; Tamayo et al., 2010). For example, studies show that the removal of particles larger than $20 \mu \mathrm{m}$ from water could effectively reduce cholera incidence by $48 \%$, suggesting that biofilms or cell aggregates contribute significantly to cholera outbreaks (Huq et al., 1996; Colwell et al., 2003).

The structural integrity of biofilms is highly dependent on the production of the biofilm matrix components (Flemming and Wingender, 2010). Upon the initial attachment mediated by mannose-sensitive hemagglutinin type IV pili and flagellum, $V$. cholerae cells show a robust ability to adhere to both biotic and abiotic surfaces (Watnick et al., 1999; Fong and Yildiz, 2007). In addition, chitin-regulated pili facilitate attachment to the chitinous exoskeleton of zooplankton (Meibom et al., 2004; Reguera and Kolter, 2005). Subsequently, V. cholerae develops 3D biofilm structures by producing EPS matrices and via cell proliferation. Multiple components of the $V$. cholerae biofilm EPS have been identified, including the key polysaccharide, Vibrio polysaccharide (VPS), and three matrix proteins, RbmA, Bap1, and RbmC (Figure 4; Teschler et al., 2015).

Vibrio cholerae cells can develop into phenotypically different colonies, i.e., rugose and smooth colony variants, in response to environmental stress (Morris et al., 1996; Wai et al., 1998; Yildiz and Schoolnik, 1999). A number of studies suggest that the rugose phenotypes are associated with an increase in VPS production. The synthesis and secretion of VPS is carried out by the products of the $v p s$-I and $v p s$-II gene clusters (Fong et al., 2010). Deleting either the $v p s$-I or the $v p s$-II cluster results in a smooth colony phenotype with no VPS production. The chemical nature of VPS has been recently determined to contain glucose, galactose, and $\mathrm{N}$-acetylglucosamine and is made of repeating units of an acetylated tetrasaccharide 


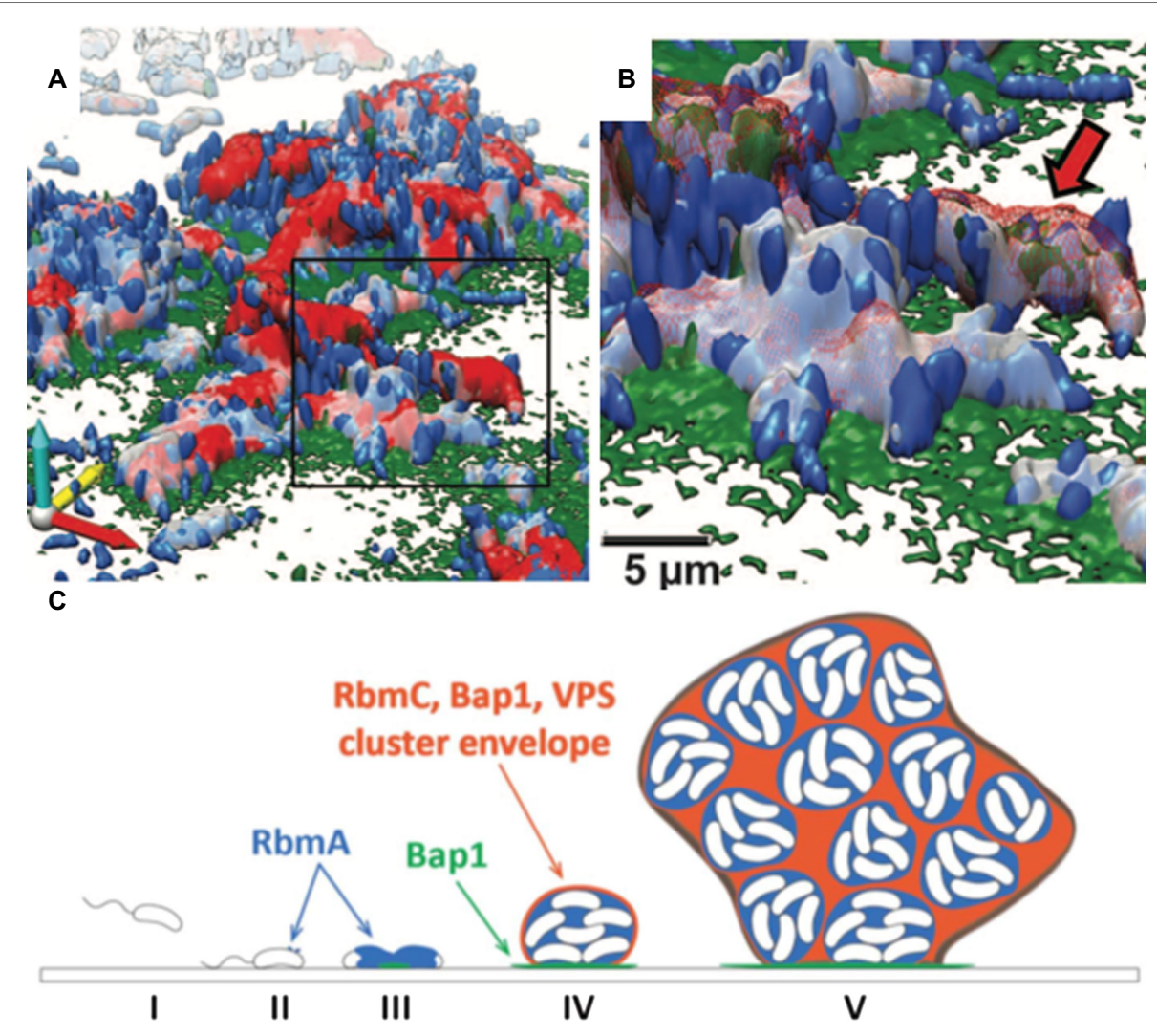

FIGURE 4 | The V. cholerae biofilm structure. (A) Three-dimensional architecture of a V. cholerae biofilm obtained through high-resolution SCLM. Images are pseudocolored in blue (cells), gray (RbmA), red (RbmC), and green (Bap1). RbmA localizes around and within the cell cluster, whereas Bap1 and RbmC encase the cell clusters. The Bap1 signal is also concentrated at the biofilm-substratum interface. (B) Enlargement of the box region in (A). The red arrow indicates one cell cluster. (C) Proposed model of biofilm development in V. cholerae. This figure is adapted with permission from Berk et al. (2012).

unique to $V$. cholerae (Yildiz et al., 2014; Reichhardt et al., 2015). VPS plays the dominant role in defining the biofilm structure of $V$. cholerae, and all accessory proteins depend on VPS to function (Figure 4; Fong et al., 2010).

Among the accessory proteins, much effort has focused on RbmA, which was first discovered as a secreted protein that changes the morphology of $V$. cholerae colonies on agar plates (Fong et al., 2006). Subsequently, RbmA was shown by highresolution microscopy to adhere biofilm cells to each other (Figures 4A,B). Structural and genetics work further demonstrates that RbmA binds VPS directly and uses a binary structural switch with its fibronectin type III (FnIII) domains to modulate its function (Giglio et al., 2013; Maestre-Reyna et al., 2013; Fong et al., 2017). During the late stages of biofilm formation, in situ proteolysis of $\mathrm{RbmA}$ promotes attachment of planktonic cells to existing biofilms (Smith et al., 2015). These foundational studies have revealed the important role of RbmA in maintaining the structural integrity of $V$. cholerae biofilms.

Less is known about how $V$. cholerae biofilms adhere to surfaces. Two proteins, biofilm-associated protein 1 (Bap1) and rugosity and biofilm structure modulator $\mathrm{C}$ (RbmC), have been suggested to contribute to the cell-to-surface adhesion in $V$. cholerae biofilms as well as to biofilm strength (Fong and Yildiz, 2007; Teschler et al., 2015; Yan et al., 2018).
While the $\Delta r b m C$ and $\Delta b a p 1$ single mutants possess colony morphology and adhesion capabilities similar to WT, double deletion of these genes results in floating biofilm clusters and an altered colony morphology (Absalon et al., 2011). This observation suggests that RbmC and Bap1 have partially redundant functions in $V$. cholerae biofilm adhesion. By using high-resolution SCLM, Berk et al. showed that the spatial distributions of Bap1 and $\mathrm{RbmC}$ are notably different at the interface between cell clusters and the substratum (Figures 4A,B; Berk et al., 2012). Bap1 appears to act as an anchor between the biofilm and the solid surface, whereas RbmC's signal was much weaker at the biofilm-substrate interface (Berk et al., 2012; Yan et al., 2016). Both Bapl and RbmC contribute to the formation of dynamic envelopes surrounding cell clusters, together with VPS (Figures 4C; Berk et al., 2012).

The close-to-full-length crystal structure of Bap1 has been recently solved (Figure 5A; Kaus et al., 2019). Bap1 consists of an eight-bladed $\beta$-propeller with a $\beta$-prism inserted within blade-6 via a flexible linker. Comparing Bap1 and RbmC, Bap1 has a 57 -amino acid insertion in its $\beta$-prism domain, which renders Bap1 and GFP fusion constructs insoluble when expressed heterologously in E. coli. This suggested that the 57-amino acid insertion could modulate the solubility of Bap1, potentially leading to surface deposition and biofilm hydrophobicity 


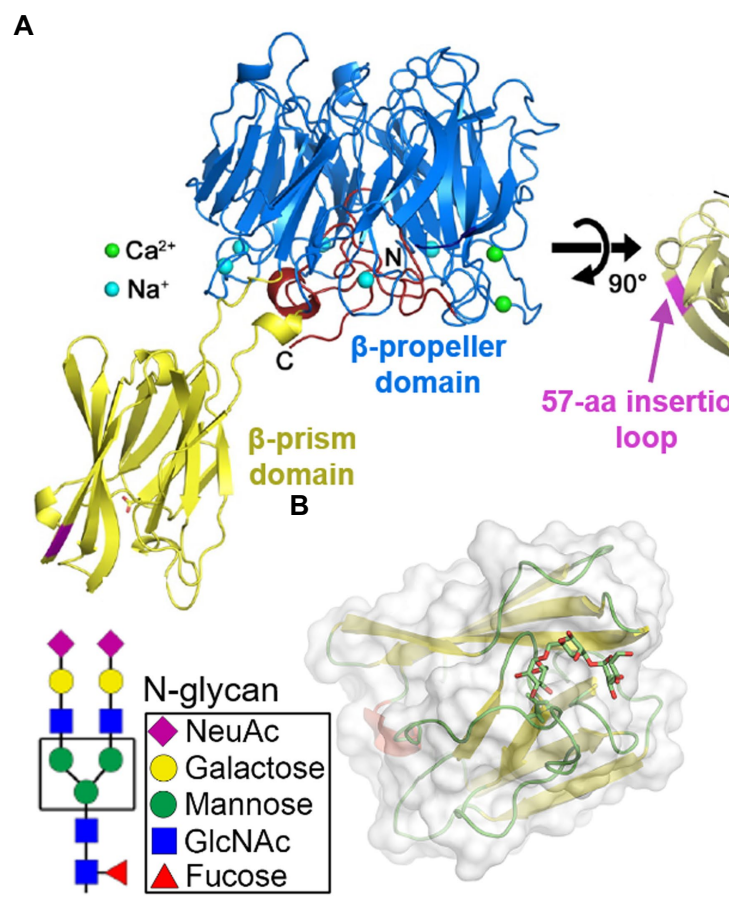

FIGURE 5 | Molecular mechanism of $V$. cholerae biofilm adhesion. (A) Crystal structure of Bap1 ${ }_{\Delta 57}(\mathrm{PDB}: 6 \mathrm{MLT})$. The 57 -amino acid insertion in the $\beta$-prism domain was removed for crystallization (indicated by magenta segment). (B) Crystal structure of the second $\beta$-prism domain of RbmC bound to mannotriose (PDB:5V6F). Inset shows the core $\mathrm{N}$-glycan structure. (C) Close-up view of the binding pocket and key residues involved in glycan binding in the $\beta$-prism. Panel (A) is adapted with permission from Kaus et al. (2019); panels (B,C) are adapted with permission from De et al. (2018).

(Berk et al., 2012; Hollenbeck et al., 2014). On the other hand, by screening against a chip-based mammalian glycan library, the $\beta$-prism domains in $\mathrm{RbmC}$ were found to favor complex $\mathrm{N}$-glycans highly presented on mammalian cell surfaces (Marth and Grewal, 2008; Moremen et al., 2012). The crystal structures of RbmC's $\beta$-prisms bound to segments of $\mathrm{N}$-glycans confirm the screening results (Figures 5B,C; De et al., 2018) and strongly suggest that $\mathrm{RbmC}$ plays a role in $\mathrm{V}$. cholerae biofilm adhesion to host intestinal surfaces. Interestingly, the binding motif between RbmC's $\beta$-prisms and N-glycan fragments is similar to that of the Vibrio cholerae cytolysin (VCC) pore-forming toxin, which is known to recognize host cell surfaces using its $\beta$-prism domain (De and Olson, 2011). As a result, even though Bap1 and RbmC share similar features and have overlapping functions (Fong and Yildiz, 2007; Absalon et al., 2011; Yan et al., 2016; Kaus et al., 2019), structural differences in their $\beta$-prisms and domain organization may potentially contribute differentially to $V$. cholerae habitation on various surfaces. However, the biophysical mechanism underlying the adhesion provided by $\mathrm{RbmC}$ and Bap1 to $V$. cholerae biofilms is still elusive.

Besides these key factors mentioned above, there are additional matrix proteins that contribute to $V$. cholerae biofilm development. Many of those factors are encoded in the $v p s$ intergenic region, downstream of $r b m A$ (Fong and Yildiz, 2007). Fong et al. demonstrated that in addition to $r b m A$ and $r b m C, r b m B, r b m D$, $r b m E$, and $r b m F$ all encode proteins that modulate $V$. cholerae rugose colony development and biofilm formation (Fong and Yildiz, 2007). Among these genes, RbmB is suggested to function as a polysaccharide lyase since the $\Delta r b m B$ mutant developed a more wrinkled colony biofilm with increased VPS accumulation, and the $\Delta r b m B$ biofilm is defective in dispersal (Singh et al., 2017; Yan et al., 2017). More recently, RbmD is suggested to contribute to biofilm formation by glycosylating other matrix proteins (Vorkapic et al., 2019), but the mechanism is still unclear. Clearly, a more comprehensive understanding of the $V$. cholerae biofilm matrix proteins and how they interact are needed.

Recent progress in single-cell resolution imaging reveals the important role of biofilm adhesion in shaping the architecture and cell ordering of $V$. cholerae biofilms. Initially, images of fixed $V$. cholerae cells obtained at different times during biofilm formation were acquired to learn how cell arrangements change as biofilms mature (Drescher et al., 2016). The community transitions from a two-dimensional (2D) branched morphology to a dense mature $3 \mathrm{D}$ cluster, in which vertical cells reside at the biofilm center and radially orientated cells are at the periphery. This entire sequence of structural transitions was subsequently visualized in living, growing $V$. cholerae biofilms (Figures 6A,B; Yan et al., 2016). Mutagenesis coupled with matrix labeling showed that $V$. cholerae biofilms lacking cellto-surface adhesion due to deletion of RbmC and Bap1 exhibit normal cell density but no cell ordering, pointing to the importance of cell-to-surface adhesion in controlling cell ordering. 

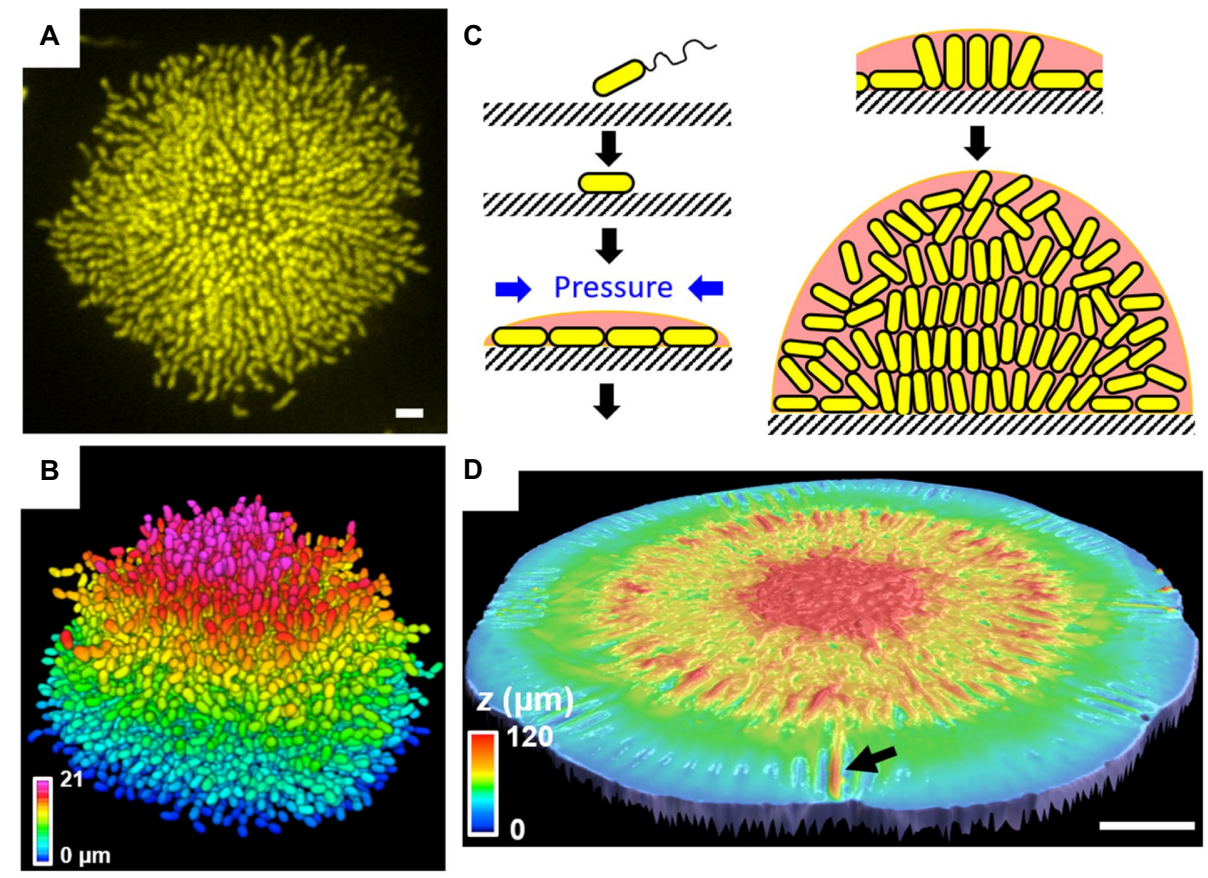

FIGURE 6 | Single-cell live imaging of $V$. cholerae biofilms. (A) Cross-sectional image of the bottom cell layer of a growing $V$. cholerae biofilm cluster at $18 \mathrm{~h}$ and (B) the corresponding segmented image with color coding according to the z position. Scale bar: $3 \mu \mathrm{m}$. (C) Schematic model of the $V$. cholerae biofilm growth process. (D) Surface topography of a $V$. cholerae colony biofilm grown on $0.5 \%$ agar at the onset of the wrinkling-to-delamination transition (36 h). The arrow indicates a delaminated blister. Scale bar: $2 \mathrm{~mm}$. Panels (A-C) are adapted with permission from Yan et al. (2016); panel (D) is adapted with permission from Yan et al. (2019).

To further explore the forces driving structural transitions in $V$. cholerae biofilms, agent-based simulations were developed to specifically address the effect of cell-to-surface interactions (Beroz et al., 2018). When a biofilm begins to form on a surface, it expands outward from the founder cell as a thin film (Figure 6C). During expansion, cells experience increasing mechanical pressure as they divide and push against their neighbors. These neighboring cells, in turn, resist the pushing force via surface adhesion. Subsequently, the pressure from these opposing forces exceeds the cell-to-surface adhesive force and causes individual cells at the center of the biofilm to reorient: They transition from aligning in parallel to aligning perpendicularly to the substrate. When verticalized cells divide, their offspring projects into the third dimension, enabling the biofilm to gradually transition from a $2 \mathrm{D}$ surface layer to a mature 3D community. How biofilm adhesion subsequently controls the radial organization of peripheral cells is still unclear.

The effect of surface adhesion on the rugose colony morphology has also been quantitatively investigated. As previously mentioned, using a capillary-peeling-based technique, the adhesive energy between the rugose $V$. cholerae biofilm and the substrate is measured to be $\sim 5 \mathrm{~mJ} / \mathrm{m}^{2}$, whereas the $\Delta r b m C \Delta b a p 1$ double mutant shows negligible adhesion in this assay (Yan et al., 2018). Mechanical measurements and modeling suggest that such wrinkled morphologies arise from a macroscopic mechanical instability (Yan et al., 2019). Specifically, it was shown that the mismatch between the growing biofilm layer and the non-growing substrate causes mechanical instabilities that enable the biofilm to transition from a flat to a wrinkled film and subsequently to a partially detached film containing delaminated blisters (Figure 6D). The mechanical compression arises from surface friction when a colony biofilm expands on the agar plate, as shown by a subsequent modeling study (Fei et al., 2020). RbmC and Bap1 have been shown to play a critical role in determining the colony morphology: When they are absent, delamination occurs easily and the delaminated blisters collapse onto each other, while the blisters in wild-type rugose colonies are homogeneously distributed throughout the colony circumference (Yan et al., 2019). While the wrinkle-to-delamination model provides the conceptual guidance to understand the rugose colony morphology, many of the morphological features remain to be explained by quantitative theories.

\section{GRAM-NEGATIVE SPECIES - PSEUDOMONAS AERUGINOSA}

Pseudomonas aeruginosa is a Gram-negative species with a large genome (6.3 million base pairs) and numerous regulatory two-component systems and transcriptional regulators, making it remarkably capable of adapting to different environments (Rodrigue et al., 2000). Biofilm formation in P. aeruginosa has been studied intensively due to its immediate clinical relevance: 
P. aeruginosa biofilms are commonly found in the defective mucus layer in the lungs of cystic fibrosis patients (Lyczak et al., 2002; Moreau-Marquis et al., 2008), as well as in chronic and burn wounds (Gjødsbøl et al., 2006; Brandenburg et al., 2019). The spatial organization of $P$. aeruginosa biofilms was first visualized by SCLM and contributes much to our current understanding of biofilm architecture in general (Lawrence et al., 1991; Reichhardt and Parsek, 2019). SCLM images show that $P$. aeruginosa biofilms have a 3D complex, hydrated structure with rod-shaped cells embedded in a matrix permeated with water channels. However, P. aeruginosa can also form different biofilm phenotypes depending on the strain and the growth conditions. For example, $P$. aeruginosa biofilms assume a characteristic "mushroom" shape when growing in flow chambers supplied with glucose as the carbon source. In contrast, $P$. aeruginosa forms flat, uniform, and densely packed biofilms when growing with citrate as the major carbon source (Klausen et al., 2003).

P. aeruginosa biofilm development has been characterized to involve five stages: reversible attachment, irreversible attachment, maturation-1, maturation-2, and dispersion (Sauer et al., 2002). In this review, we will primarily focus on the adhesive aspects of $P$. aeruginosa biofilms and the reversible and irreversible attachment stages; biofilm development and its regulation in $P$. aeruginosa have been extensively reviewed elsewhere (O'Toole and Wong, 2016; Rumbaugh and Sauer, 2020; Thi et al., 2020). In the reversible attachment stage, planktonic $P$. aeruginosa cells use their polar flagella to swim toward a substrate and temporarily adhere via their cell poles (O'Toole and Kolter, 1998; Schniederberend et al., 2019). At this stage, attachment is still reversible, and adhesion is achieved through weak, reversible interactions, including van der Waals forces. Once attached, $P$. aeruginosa cells twitch by extending and retracting their type IV pili on a surface (Chiang and Burrows, 2003; Limoli et al., 2019). Type IV pili are hair-like protein polymers that enable adhesion to host cells and surfaces (Burrows, 2012). The type IV pili are also crucial for mediating irreversible cell-to-surface attachment, colonization, DNA uptake, and virulence induction (Saiman et al., 1990; Zoutman et al., 1991).

In stage II, $P$. aeruginosa cells initiate irreversible attachment by generating strong adhesive forces and aligning their long axes parallel to the surface (O'Toole and Kolter, 1998). The local cell density increases through population growth, setting the stage for subsequent biofilm formation (Ha and O'Toole, 2015). In the context of infection, the type IV pilus is also believed to initiate the adhesion between $P$. aeruginosa cells and the host surface (Laventie et al., 2019). For instance, studies have shown that the type IV pili bind directly to the glycolipids asialo-GM1 and asialo-GM2 on epithelial cell surfaces (Comolli et al., 1999). The type IV pilus protein, PilY1, is a pilus-associated adhesin that has been proposed to be required for type IV pili biogenesis and attachment of $P$. aeruginosa to human tissue (Heiniger et al., 2010; Kuchma et al., 2010; Johnson et al., 2011). Luo et al. compared the aspect ratio (Figure 7A) of 2D projections of the pilY1 mutant with that of WT cells (Luo et al., 2015). In the reversible attachment
A

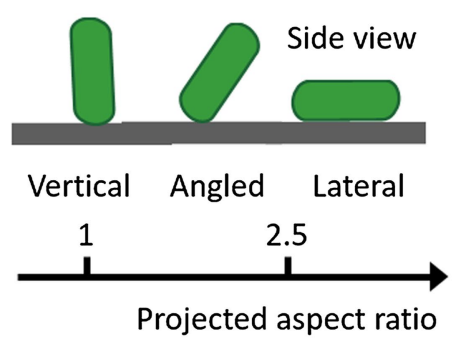

B

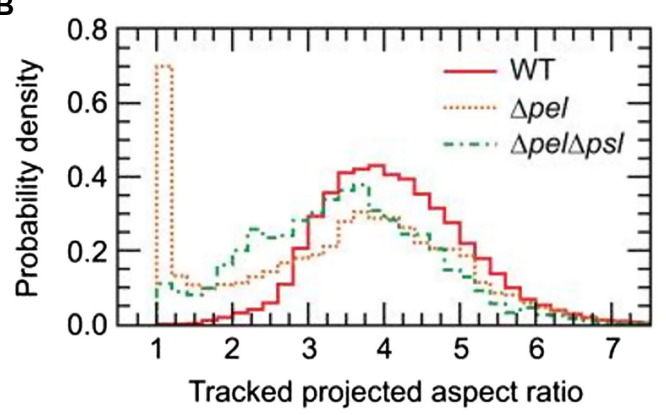

C

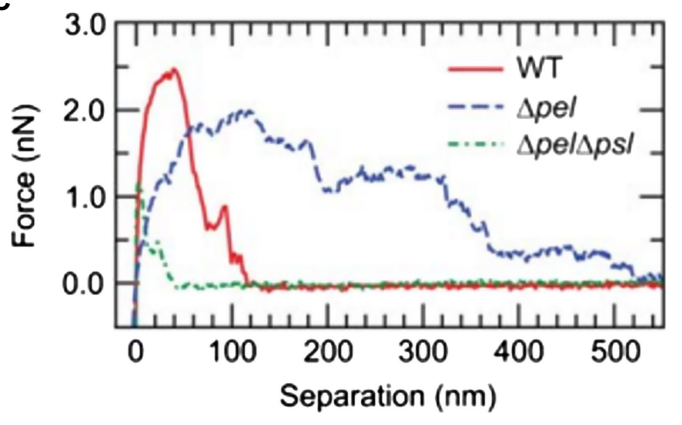

FIGURE 7 | Analysis of the initial attachment phase of $P$. aeruginosa. (A) Schematic representation of the cell aspect ratio in a 2D projection. (B) Normalized histograms of the projected aspect ratios of WT, $\Delta p s l$, and $\Delta p e l \Delta p s / P$. aeruginosa cells. The position of the main peak for the $\Delta p e l \Delta p s /$ strain is shifted to the left of the main peak for WT and $\Delta p s /$ strains, indicating that the $\Delta p e l \Delta p s /$ cells spend more time in a configuration tilted from the surface. For $\Delta p s /$ cells, a second peak near 1 appears, corresponding to bacteria standing vertically on the substrate. (C) Representative individual force curves, showing adhesive characteristics of each strain. $\Delta p e / \Delta p s /$ has an adhesion range significantly shorter than that of WT. $\Delta$ pel has a longer range of adhesion, but the magnitude is smaller than that of WT. Panels (B,C) are adapted with permission from Cooley et al. (2013).

stage, both the pilY1 mutant and WT cells vertically adhere to the surface with a projected aspect ratio around 1. However, in the irreversible attachment stage, the pilY1 mutant has an average projected aspect ratio significantly smaller than the laterally adhered WT cells, indicating weaker adhesion. They further showed that PilY1 regulates cell-to-surface attachment via two separate mechanisms: (i) The Pil-Chp complex senses external signals to induce cAMP production, and cAMP, in turn, activates the transcription of pilY1 gene and (ii) the PilY1 located on the outer membrane can induce activity of the diguanylate cyclase SadC by signaling through type IV pili. SadC has a GGDEF domain that catalyzes 
c-di-GMP production and therefore promotes biofilm formation (Simm et al., 2004; O’Toole and Wong, 2016).

After the initial attachment stages, $P$. aeruginosa cells aggregate to form clusters by producing EPS, which generates a more potent adhesive force allowing cell clusters to irreversibly attach to the surface. EPS also promotes biofilm mechanical strength by enhancing cell-to-cell cohesion. In P. aeruginosa, EPS consists of several polysaccharides, proteins, nucleic acids, and lipids. $P$. aeruginosa employs three major exopolysaccharides: alginate, Psl (polysaccharide synthesis locus), and Pel (pellicle polysaccharide; Ghafoor et al., 2011). Alginate is a linear polysaccharide composed of $\mathrm{D}$-mannuronic acid and L-guluronic acid, which is the main structural component in mucoid $P$. aeruginosa biofilms. Biofilms formed by non-mucoid $P$. aeruginosa strains primarily use Pel and Psl exopolysaccharides (Colvin et al., 2012). Several studies have shown that Psl is mainly involved in the initial attachment of cells and early biofilm formation, whereas Pel is essential for late-stage biofilm formation and maturation (Friedman and Kolter, 2004; Jackson et al., 2004; Overhage et al., 2005; Campisano et al., 2006; Ghafoor et al., 2011). Psl is a mannose-rich, branched polysaccharide containing D-mannose, D-glucose, and L-rhamnose (Byrd et al., 2009), and it acts as a "molecular glue" to help $P$. aeruginosa attach to biotic and abiotic surfaces and initiate biofilm formation (Friedman and Kolter, 2004; Ma et al., 2006; Byrd et al., 2010; Zhao et al., 2013; Jones and Wozniak, 2017). In a mature biofilm, Psl contributes to the biofilm mushroom cap by forming a peripheral meshwork covering the cap region (Ma et al., 2006, 2009). Pel has recently been characterized as a $\mathrm{N}$-acetyl glucosamine- and $\mathrm{N}$-acetyl galactosamine-rich polysaccharide (Jennings et al., 2015). It has been shown to play a critical role in pellicle formation at the air-liquid interface, and it interacts with eDNA in the matrix through electrostatic interactions (Jennings et al., 2021). In the laboratory strain PAO1, Psl has been shown to contribute significantly to the formation of characteristic mushroom-shaped biofilms, whereas Pel contributes mainly to the biofilm cell density and/or compactness and remodeling in the late stage (Ghafoor et al., 2011; Chew et al., 2015). In the PA14 strain, however, Pel is the dominant extracellular polysaccharide and is essential for the wrinkled colony phenotype observed on agar plates (Friedman and Kolter, 2004). It will be interesting, in the future, to apply the above wrinkle-to-delamination model to PA14 colony biofilms to test the generality of the model to other systems.

Studies focused on the biophysical and biomechanical mechanisms of how $P$. aeruginosa cells attach to surfaces and self-organize into biofilms have revealed Psl as a key component of adhesion. For instance, Zhao et al. used cell-tracking algorithms in combination with Psl staining to map the spatial characteristics of cell-to-surface interactions for WT $P$. aeruginosa as well as for the $\Delta p s l D$ mutant deficient in Psl production (Zhao et al., 2013). Their study shows that the surface exploration patterns of WT and $\Delta p s l D P$. aeruginosa are dramatically different (Figures 8A,B). WT $P$. aeruginosa cells migrate across a substratum leaving Psl footprints, which in turn enhance subsequent cell adhesion and eventual promotion of microcolony formation (Figures 8C,D). They dubbed this phenomenon "the rich get richer." The $\Delta p s l D$ mutant does not display this phenomenon. To explain this difference, they proposed that type IV pili favor Psl-rich regions pulling cells toward these regions. Later, Cooley et al. used optical microscopy in combination with AFM to examine the role of these polysaccharides in promoting cell-to-surface adhesion (Figures 7B,C; Cooley et al., 2013). Their result demonstrates that Pel alone can provide some transient cell-to-surface attachment, but not as permanent as Psl. Furthermore, force measurements showed that Psl generates short-ranged and localized adhesive forces, whereas Pel generates weaker but longer-ranged adhesive forces. By comparing the projected aspect ratio of $\Delta p s l, \Delta p e l$, and WT cells, the authors reached the conclusion that Pel controls the attachment geometry by helping the rod-shaped $P$. aeruginosa cells lie parallel to the substrate. Therefore, the $\Delta p e l$ strain can still permanently adhere to a surface, but with only one end attached, whereas the WT cells can lie parallel to surface with little to no tilting. How Psl and Pel interact at the molecular level to ensure the parallel alignment remains to be demonstrated.

In addition to the critical role of exopolysaccharides, eDNA makes an important contribution to $P$. aeruginosa biofilm formation. eDNA binds to $\mathrm{Ca}^{2+}$ forming "cationic bridging" and therefore overcomes the electrostatic repulsion between negatively charged polysaccharide strands (Bos et al., 1999; Whitchurch et al., 2002; Flemming et al., 2007; Das et al., 2014; Powell et al., 2018). The cationic bridge also helps initial adhesion to foreign surfaces, facilitates cell aggregation, and strengthens $P$. aeruginosa biofilms. Furthermore, eDNA can interact with Pel and Psl to form fiber-like networks that likely promote stability of the biofilm (Jennings et al., 2015; Wang et al., 2015; Jennings et al., 2021).

Finally, accessory proteins also exist in the $P$. aeruginosa biofilm matrix, but their roles are not well understood at this time. The best characterized matrix protein is CdrA. CdrA is an extracellular adhesin that is found in both cell-associated and secreted forms in biofilms. CdrA is secreted out of the cell as cargo of the CdrA-CdrB two-partner secretion system (Reichhardt et al., 2018). Full-length CdrA is a $220 \mathrm{kDa}$ protein that is processed by a poorly understood proteolysis mechanism to generate a $150 \mathrm{kDa}$ truncated released form of the protein. Recent studies indicate that the C-terminus of CdrA is cleaved by the periplasmic protease LapG (Rybtke et al., 2015; Cooley et al., 2016). LapG is regulated by the intracellular levels of c-di-GMP such that under conditions of low c-di-GMP, LapG cleaves cell-associated CdrA at a C-terminal TAAG site to release $\mathrm{CdrA}$ into the environment. CdrA contributes to the maintenance of the structural integrity of $P$. aeruginosa aggregates via CdrA-Psl, CdrA-Pel, and CdrA-CdrA interactions (Borlee et al., 2010; Reichhardt et al., 2018, 2020). Interestingly, CdrA can also promote cell clustering without EPS (Reichhardt et al., 2018); the exact mechanism is unclear.

In addition to CdrA, $P$. aeruginosa also produces two small soluble lectins, LecA and LecB, that bind to the repeating sugar unit in the exopolysaccharide and help $P$. aeruginosa adhere to targets in the host organism (Mitchell et al., 2005; Visini et al., 2015; 


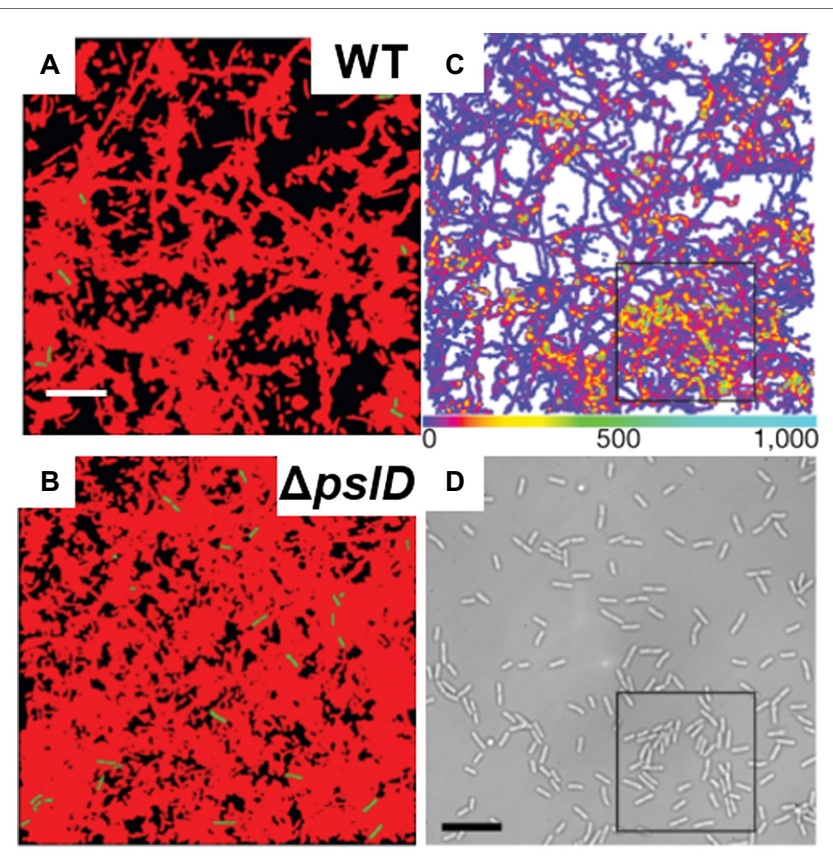

FIGURE 8 | $P$. aeruginosa adhesion controls surface motility and colonization. (A) and (B) illustrate the efficiency of surface coverage by bacterial trajectories with Psl trails. Shown are cumulative surface coverage images at $5 \mathrm{~h}$ for WT (A) and $\Delta p s I D(\mathbf{B})$, respectively. Red corresponds to areas visited by $P$. aeruginosa, and black corresponds to the unvisited areas. (C) Visit frequency map of WT cells for the first $15.7 \mathrm{~h}$ after inoculation, when microcolonies are just starting to form. The black square indicates an example of colony formation. (D) The brightfield image corresponding to (C). Scale bars, $10 \mu \mathrm{m}$. This figure is reproduced with permission from Zhao et al. (2013).

Passos da Silva et al., 2019). In particular, LecA is a tetrameric protein that binds to sugars, such as $\mathrm{N}$-acetyl-D-galactosamine, galactose, and glucose. Although each $12.8 \mathrm{kDa}$ LecA monomer has a calcium-dependent binding site for galactose and an independent binding site for glucose, it is unclear if LecA binds to Psl, Pel, or both (Mitchell et al., 2002; Blanchard et al., 2014). In contrast, LecB binds to mannose residues along the backbone of Psl to promote the retention of Psl within the biofilm matrix (Passos da Silva et al., 2019). LecB is a tetrameric protein comprised of four $11.7 \mathrm{kDa}$ subunits each containing a calciumdependent ligand binding site (Loris et al., 2003) and is associated with the outer membrane porin OprF (Funken et al., 2012). An interesting direction for future endeavors would be to search for extracellular proteins in $P$. aeruginosa biofilms that, like $\mathrm{RbmC}$ and Bap1 in V. cholerae, serve as biofilm-specific adhesins.

\section{GRAM-POSITIVE SPECIES - STAPHYLOCOCCUS AUREUS AND OTHER STAPHYLOCOCCI}

Gram-positive pathogens produce various factors known as cell wall-associated (CWA) proteins that are attached to the thick peptidoglycan cell wall through covalent linkages.
Many Gram-positive strains use CWA proteins to bind to components of the mammalian extracellular matrix (ECM), such as fibrinogen, fibronectin, and cytokeratin, which, in turn, associate with proteins found on the surface of mammalian cells (Geoghegan et al., 2009; Hymes and Klaenhammer, 2016). Due to the high affinity of binding to the mammalian ECM, S. aureus is one of the major Gram-positive pathogens that causes acute, chronic, and sometimes life-threatening biofilm-associated diseases in humans, including sepsis, endocarditis, osteomyelitis, and pneumonia. S. aureus has the capacity to attach to both biotic and abiotic surfaces, resulting in a high probability of being introduced during the implantation of medical devices (Heilmann, 2011).

Attachment of staphylococci to abiotic surfaces is thought to be facilitated by various physical forces, such as hydrogenbonding, ionic, and hydrophobic interactions. For example, AFM measurements have shown that on hydrophobic surfaces, adhesion of the hydrophobic staphylococcal cells is instantaneous, while on hydrophilic glass, gradual strengthening of the interaction is observed, which is attributed to hydrogen bond formation (Boks et al., 2008). The interaction range can be as long as $50 \mathrm{~nm}$, suggesting that large surface-associated structures are responsible for adhesion (Thewes et al., 2014). In vitro, staphylococci can form biofilms on abiotic surfaces, but biofilm adhesion and formation are significantly enhanced if the surfaces are treated with ECM-containing media, or simply fibronectin (Chen et al., 2012; Kim et al., 2014). In vivo, direct contact between staphylococcal cells and abiotic surfaces is considered not relevant because the inserted abiotic surfaces are covered with ECM, with fibronectin being the dominant factor (Francois et al., 2000; Otto, 2008). Therefore, below we focus on the proteins responsible for the staphylococci-ECM interaction.

The most well-studied CWA proteins belong to the family of microbial surface component recognizing adhesive matrix molecules (MSCRAMMs). MSCRAMMs include a wide variety of adhesins, many of which have the ability to bind multiple ligands resulting in some degree of crosstalk between adhesins and target ligands. MSCRAMMs are present abundantly in many Gram-positive species, such as Staphylococcus pseudintermedius and Enterococci faecalis (Liu et al., 2007; Ponnuraj and Narayana, 2007; Bannoehr et al., 2011). S. aureus has about 20 MSCRAMMs, many with multiple target ligands that can bind to different surfaces in different environments (Foster et al., 2014). A common feature of S. aureus adhesins within the MSCRAMM protein family is the tandemly-linked IgG-like folds (Foster et al., 2014). The defining feature of CWAs is a conserved LPXTG motif at their C-terminus, which is involved in anchoring these proteins to bacterial peptidoglycans in the cell envelope (Mazmanian et al., 1999; Clarke and Foster, 2006).

The versatile nature of MSCRAMM adhesins allows $S$. aureus to attach to a wide range of surfaces of both biotic and abiotic origin. On biotic surfaces, the cell-to-surface interactions are well-defined through specific ligand binding. For example, collagen-binding adhesin, fibronectin-binding proteins, and fibrinogen-binding proteins are some MSCRAMMs that enable 
S. aureus to attach to the mammalian ECM. Ponnuraj et al. proposed a binding mechanism called "dock, lock, and latch (DLL)" that describes the mode of action for a fibrinogenbinding MSCRAMM protein in S. epidermidis called SdrG (Ponnuraj et al., 2003). The crystal structure (Figure 9A) of the fibrinogen binding domain in SdrG has a similar structure to the Sdr family protein SdrE in S. aureus discovered later (Ponnuraj et al., 2003; Luo et al., 2017). Well-defined electron density for most of the residues of the fibrinogen-derived peptide is observed in the crystal structure, indicating that the peptide fits tightly into the cleft of SdrG's binding domain. The DLL mechanism describes a multiple-step adhesion process: First, the C-terminal domain of SdrG forms a cover, which allows it to "lock" on to a "docked" peptide and subsequently sequester the "docked" peptide by "latching" onto the neighboring N2 domain (Figures 9B,C; Milles et al., 2018). Due to the high structural similarity of the proteins in the MSCRAMM family, it has been suggested that this DLL mechanism could be generalized to other structurally similar CWA proteins, such as FnBPA and SdrE (Ponnuraj et al., 2003; O'Neill et al., 2008; Zhang et al., 2017).

Recently, Milles et al. performed AFM-based single-molecule force spectroscopy to show that SdrG binds to the N-terminus of the $\beta$-chain of human fibrinogen (Fg) with ultra-strong $(\sim 2 \mathrm{nN})$ forces, comparable to covalent interactions (Milles et al., 2018). More interestingly, this strong binding is independent of the side chains on Fg (Milles et al., 2018). The underlying molecular mechanism for the side-chain independence is that the DLL mechanism creates a deep and rigid binding pocket to confine the peptide target in a stable geometry, which only relies on backbone hydrogen bonds. The authors also used steered molecular dynamics simulations to corroborate the AFM measurements and showed that other adhesins from S. aureus, including the clumping factors A and B (ClfA and ClfB), SdrE, and FnBPA, all have such side-chain-independent mechanostability. Such side-chain-independent mechanism might confer an invasive advantage to staphylococci. Similarly, in a subsequent work, Prystopiuk et al. unraveled the molecular interactions underlying the three-component FnBPA-Fn-integrin system (Figure 10A; Prystopiuk et al., 2018). S. aureus adheres to endothelial cells via Fn bridges, established by FnBPA binding to $\alpha 5 \beta 1$ integrins on the host cell surface (Sinha et al., 1999; Massey et al., 2001; Sinha and Herrmann, 2005; Edwards et al., 2010). Their results demonstrated that FnBPA mediates bacterial adhesion to soluble Fn via strong forces $(\sim 1.5 \mathrm{nN})$ comparable to $\mathrm{SdrG}$-Fg $\beta$ binding (Figure 10B), using a $\beta$-zipper mechanism (Prystopiuk et al., 2018).

Interestingly, $S$. aureus adhesion can be enhanced by shear forces (Geoghegan and Dufrene, 2018). For example, under high-shear conditions, ClfA binds to fibrinogen and promotes platelet capture, leading to thrombus formation. Over the past few years, an increasing number of studies have demonstrated that the $S$. aureus adhesins ClfA and ClfB can act as force-sensitive molecular switches to promote cell-tosurface adhesion under mechanical stress (Vitry et al., 2017; Herman-Bausier et al., 2018). Dufrene et al. showed that at low tensile force, the bond between ClfA and immobilized fibrinogen is weak ( $0.1 \mathrm{nN}$; Herman-Bausier et al., 2018); however, with mechanical tension, the bonding force increases to $\sim 1.5 \mathrm{nN}$. In a parallel study by the same group, it was found that $\mathrm{ClfB}$ adheres to loricrin through similar dynamic conformational changes (Vitry et al., 2017). They also demonstrated that the strength of the ClfB-loricrin interaction increases with mechanical tension. In both cases, an adhesive force of $1.5-2 \mathrm{nN}$ is typically measured at high mechanical tension, which corresponds to the strength of single DLL-like bonding interactions. Together, these unique adhesion mechanisms enable $S$. aureus cells to modulate adhesion by sensing external forces at the molecular level, which provides significant advantages during colonization.

$S$. aureus also possesses adhesins that are not covalently attached to the cell wall. The major adhesins in this class are secretable expanded repertoire adhesion molecules (SERAMs), including the extracellular fibrinogen binding protein, extracellular matrix binding protein, and extracellular adherence protein (Eap, also known as Map and p70). Eap is the most well-studied protein in the SERAMs family. The protein sequence of Eap lacks the LPXTG motif, suggesting that Eap is associated but not covalently linked to the peptidoglycan cell wall. Over the past few decades, Eap has been shown to be an anchorless
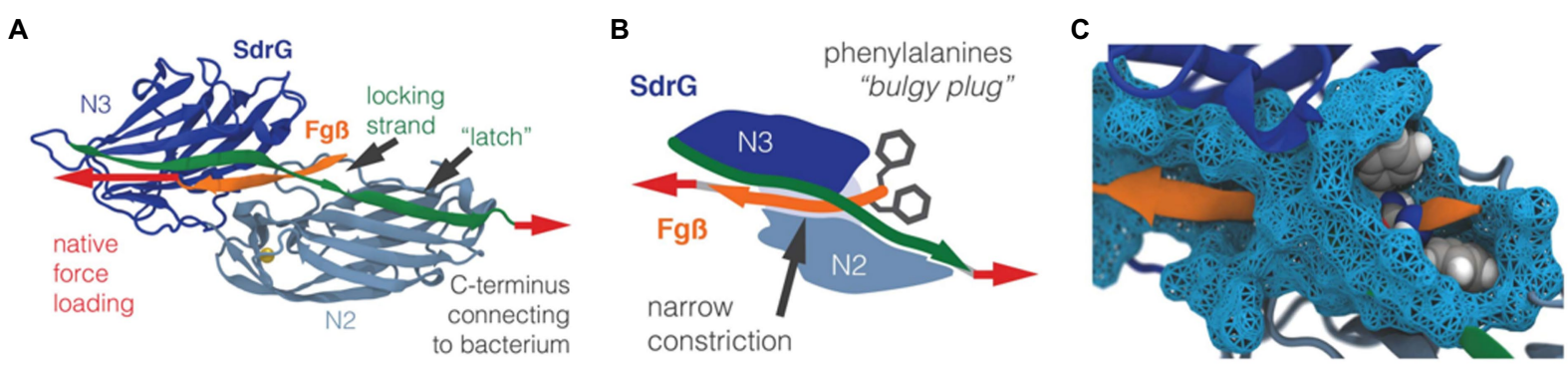

FIGURE 9 | Structure of the SdrG-Fg $\beta$ complex. (A) The crystal structure of the SdrG (blue): Fg $\beta$ (orange) complex. The locking strand (green) encloses the peptide in the binding pocket between the Ig-fold N2 (light blue) and N3 (dark blue) domains and a calcium (yellow) binding loop. The red arrows indicate the force applied to the molecular complex. (B) Schematic of the "bulgy plug" hypothesis. The bulky phenylalanine side chains (gray) of Fg $\beta$ (orange) are blocked by the locking strand (green). (C) Crystal structure showing the bulky phenylalanine side chains in van der Waals representation (gray spheres) of Fg $\beta$ (orange), which have to wiggle through a narrow constriction (cyan surface). This figure is adapted with permission from Milles et al. (2018). 
A Fn-binding repeats
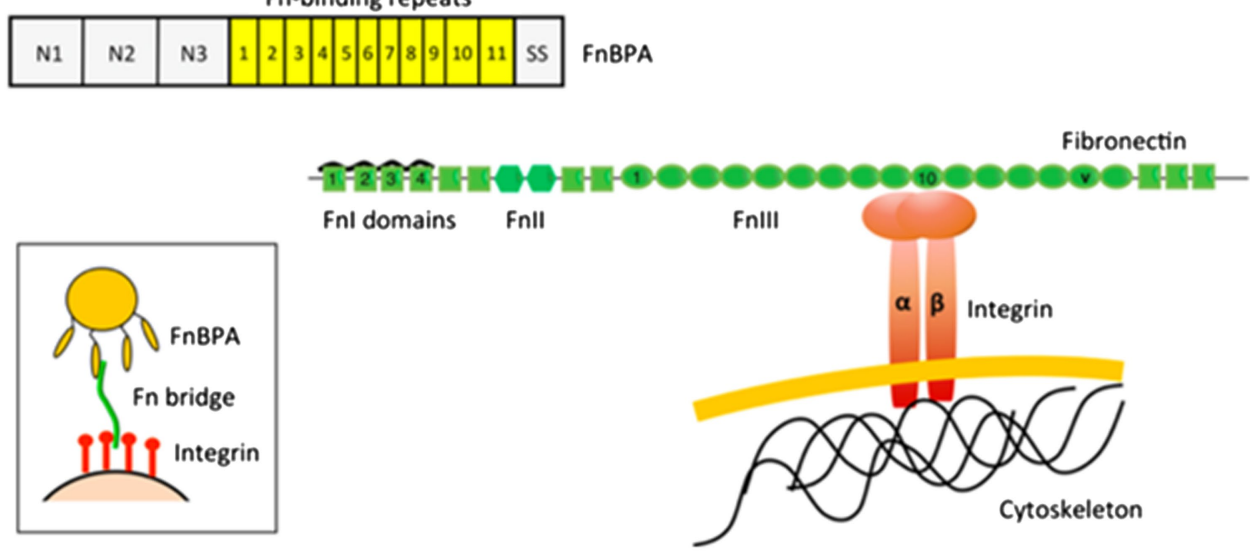

B

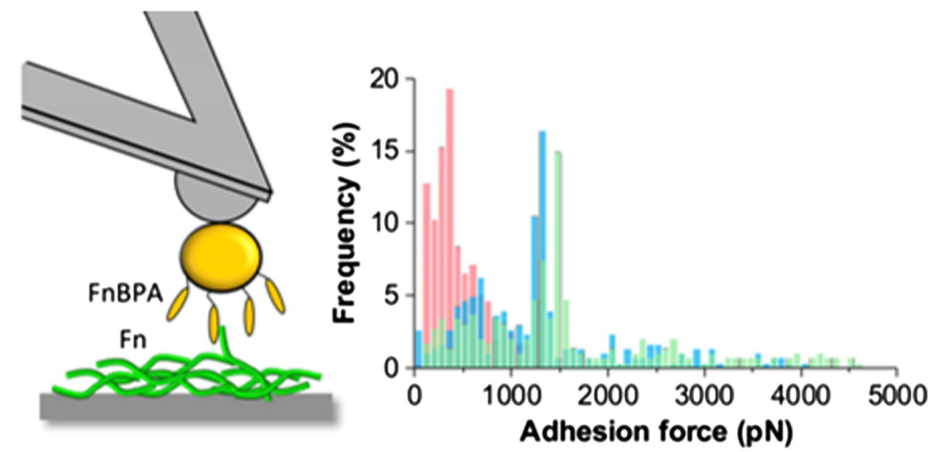

FIGURE 10 | The three-component FnBPA-fibronectin-(Fn)-integrin system. (A) Mechanism of FnBP-dependent cell invasion by S. aureus. The main invasion pathway of $S$. aureus involves interaction of the Fn-binding repeats of FnBPA with type I Fn modules via a tandem $\beta$-zipper structure. This triggers a conformational change in Fn, resulting in the exposure of the cryptic integrin-binding site in the tenth Fnlll module, which in turn engages in a high-affinity interaction with the $\alpha 5 \beta 1$ integrin found on the membrane of mammalian cells. (B) Maximum adhesion force histograms obtained by recording force-distance curves between $S$. aureus cells and Fn immobilized on solid substrates. This figure is adapted with permission from Prystopiuk et al. (2018).

protein that contributes to staphylococcal adhesion and is capable of modulating the inflammatory response via interactions with the glycoprotein ICAM-1. While Eap has been shown to bind a number of host extracellular components, the exact mechanism of how Eap is involved in bacterial adhesion to these components is still unclear (Hammel et al., 2007; Geraci et al., 2017).

The adhesion proteins mentioned above are mostly produced and primarily important during the initial cell attachment phase. In staphylococci, the formation of a biofilm structure further requires the production of polysaccharide intercellular adhesin (PIA) and the release of eDNA from dead cells. PIA is synthesized by enzymes encoded by the icaADBC operon and plays a crucial role in the accumulation of biofilms (Fluckiger et al., 2005; Archer et al., 2011). Vuong et al. suggested that PIA may aid in the extracellular biofilm matrix stickiness via its electrostatic interaction with other surface polymers (Vuong et al., 2004). More recently, Ganesan et al. purified PIA from Staphylococcus epidermidis and measured its molecular mass (Ganesan et al., 2013). Using extensive rheological tools, they have quantitated the entanglement and association contribution to its polymer properties. More recently, the same group showed that the positively charged PIA molecules electrostatically interact with the negatively charged cells to form phase-separated, biofilm-like aggregates (Stewart et al., 2015). They suggested that such a phase separation mechanism underlies the mechanical properties of S. epidermidis biofilms (Stewart et al., 2015). An interesting mechanistic question for future exploration is the potential synergistic interaction between PIA (or other cell-cell aggregation factors) and the MSCRAMMs.

Furthermore, some staphylococci can also form PIA-independent biofilms; in these biofilms, several surfaceassociated proteins contribute to biofilm development and promote intercellular adhesion, such as the biofilm-associated protein (Bap; Cucarella et al., 2001; Tormo et al., 2005; Lasa and Penadés, 2006). Bap, a large protein of 2,276 amino acids, was first discovered through a transposon screen using adhesion to polystyrene surfaces as a phenotype (Cucarella et al., 2001); it is suggested to be involved in the primary adhesion to abiotic surfaces as well as in biofilm formation. Bap is anchored to the cell wall and subsequently undergoes processing to release fragments of the $\mathrm{N}$-terminal domain, which self-assemble into amyloid fibers to form the biofilm scaffold (Taglialegna et al., 2016). This self-assembly process only takes place under low $\mathrm{Ca}^{2+}$ concentrations and acidic $\mathrm{pH}$, suggesting that Bap 
also acts as a sensor of the extracellular environment (Taglialegna et al., 2016). So far, the bap gene has only been found in $S$. aureus isolates from bovine but not from human (Cucarella et al., 2004). S. epidermidis carries bhp, a homology of bap, but $b h p$ does not seem to be involved in biofilm formation (Lasa and Penadés, 2006). On the other hand, S. xylosus forms Bap-dependent biofilms (Schiffer et al., 2019). Many mysteries still surround this relatively new biofilm adhesin in terms of its structure, function, distribution in staphylococci, and involvement in pathogenicity.

Another interesting class of matrix protein in staphylococci biofilms is accumulation-associated protein (Aap) in S. epidermis and $S$. aureus surface protein G (SasG) in S. aureus. Aap and SasG share $54 \%$ sequence identity; they both possess a signal peptide at the $\mathrm{N}$-terminus, followed by an $\mathrm{A}$ domain and a $B$ region with 3-12 repeating G5 and E domains of 128 amino acids (Conlon et al., 2014). These proteins also have a LPDTG motif at their C-terminus, suggesting that they are CWAs. Expression of SasG or Aap causes biofilm formation, and this induction is independent of PIA (Rohde et al., 2005; Corrigan et al., 2007). Functional Aap $(220 \mathrm{kDa})$ requires proteolytic processing into a truncated $140 \mathrm{kDa}$ fragment in which the A domain is cleaved (Hussain et al., 1997; Conlon et al., 2014). The unprocessed form of Aap with an intact A domain has been shown to promote primary surface adhesion only in some specific strains (Conlon et al., 2014). More generally, cleavage is necessary to expose the $\mathrm{B}$ region and promote cell-cell adhesion via two distinct $\mathrm{Zn}^{2+}$-dependent mechanisms: (1) the $B$ region forming twisted rope-like structures between neighboring cells, catalyzed by $\mathrm{Zn}^{2+}$ (Conrady et al., 2013), and (2) the B-repeat self-assembling into functional amyloid fibers (Yarawsky et al., 2020). Interestingly, expression of SasG inhibits the MSCRAMM-mediated adhesion to host surfaces a steric hindrance caused by SasG fibrils prevents short-ranged interactions with MSCRAMMs (Corrigan et al., 2007). This observation leads to the interesting question of how staphylococci deploy competing adhesion mechanisms to ensure successful colonization and dispersal in the host.

In summary, $S$. aureus cells use their unique adhesive mechanisms to colonize biotic surfaces in humans, rendering $S$. aureus a common opportunistic bacterial species in many contexts. Biofilm formation is closely associated with pathogenicity in $S$. aureus. For example, Parastan et al. reported a significant correlation between the adhesion-related genes and multidrug resistance patterns of $S$. aureus clinical isolates (Parastan et al., 2020). The MSCRAMMs and other less-understood adhesion mechanisms all help staphylococci invade the human body and evade the immune system. Therefore, a better understanding of the adhesion mechanism of $S$. aureus can facilitate the development of new drugs targeting the adhesins of $S$. aureus and inhibit its surface attachment during infection.

\section{CONCLUSION AND OUTLOOK}

Much remains to be learned regarding how microbes develop their communal attachment to a wide range of foreign surfaces.
Different species achieve biofilm adhesion through different mechanisms: In the examples reviewed here, $V$. cholerae possesses specific matrix proteins that, in conjunction with the exopolysaccharide, achieve adhesion of the entire biofilm. On the other hand, $P$. aeruginosa biofilms appear to use their major exopolysaccharide, jointly with pili, for surface adhesion. Finally, staphylococci exhibit multiple biofilm-forming strategies: Some strategies depend on exopolysaccharide and ECM-binding adhesins, while others depend on the formation of amyloid fibers. Indeed, it seems that the Aap/SasG- or Bap-dependent biofilm formation pathways are orthogonal to the exopolysaccharide-based strategy. This might not be unique to staphylococci; V. cholerae is also known to form VPS-independent biofilms (Kierek and Watnick, 2003; Müller et al., 2007). A central scheme that starts to emerge for biofilm adhesion is the dual function of the glue: The adhesion molecules need to attach to the biofilm-dwelling cells on one side, either through direct anchoring or indirectly through exopolysaccharide; on the other hand, the adhesin needs to attach to a foreign surface, be it a bare abiotic surface or a host surface decorated with specific molecules. It is unclear what the advantages and disadvantages of the different strategies are, partly due to our limited knowledge about the biochemical details of many of the adhesive molecules and their interactions with foreign surfaces.

Looking forward, we propose following research avenues to further enrich our understanding of biofilm adhesion:

(1) Structural biology: More crystal structures of the adhesins need to be solved to build our understanding of bacterial adhesion to specific biotic surfaces. The recent rapid progress in cryo-EM could be harnessed for structural solving (Cheng et al., 2015), and classical X-ray crystallography can provide high-resolution details of ligand binding motifs.

(2) Biophysical characterization: While AFM has become a powerful tool in the study of bacterial adhesion, significant technical expertise is required to perform and interpret AFM experiments. Closer collaboration between microbiologists and biophysicists will certainly lead to many new discoveries regarding bacterial adhesion.

(3) The connection between cell adhesion and biofilm architecture should be further explored in other species. So far, the single-cell biofilm imaging technique has mainly been applied to $V$. cholerae biofilms, revealing well-defined cell ordering that is highly dependent on cell-to-surface adhesion. It remains to be seen whether such cell ordering is a general phenomenon in all biofilm-forming species.

(4) Molecular scale information has yet to be connected with bulk adhesion measurements. Many techniques reviewed here reveal the adhesive energy between bulk biofilms (such as a colony biofilm) and a substrate; it is unclear how to compare AFM measurements at the cellular level to these bulk measurements.

We believe that with coordinated efforts from microbiologists, biophysicists, and engineers, the secret ingredients of biofilm adhesion will be uncovered in the near future. A comprehensive understanding of biofilm adhesion will pave the way for the 
discovery of new chemicals that specifically target biofilm-surface interactions and lead to more forward-looking, innovative functional biofilm materials that adhere to various surfaces on demand.

\section{AUTHOR CONTRIBUTIONS}

ZJ reviewed the literature and complied the review. TN, SM, $\mathrm{RO}$, and JY revised the initial draft and reviewed the final draft.

\section{REFERENCES}

Absalon, C., Van Dellen, K., and Watnick, P. I. (2011). A communal bacterial adhesin anchors biofilm and bystander cells to surfaces. PLoS Pathog. 7:e1002210. doi: 10.1371/journal.ppat.1002210

Alam, M., Sultana, M., Nair, G. B., Siddique, A. K., Hasan, N. A., Sack, R. B., et al. (2007). Viable but nonculturable Vibrio cholerae O1 in biofilms in the aquatic environment and their role in cholera transmission. Proc. Natl. Acad. Sci. U. S. A. 104, 17801-17806. doi: 10.1073/pnas.0705599104

Archer, N. K., Mazaitis, M. J., Costerton, J. W., Leid, J. G., Powers, M. E., and Shirtliff, M. E. (2011). Staphylococcus aureus biofilms: properties, regulation, and roles in human disease. Virulence 2, 445-459. doi: 10.4161/viru.2.5.17724

Autumn, K., Niewiarowski, P. H., and Puthoff, J. B. (2014). Gecko adhesion as a model system for integrative biology, interdisciplinary science, and bioinspired engineering. Annu. Rev. Ecol. Evol. Syst. 45, 445-470. doi: 10.1146/ annurev-ecolsys-120213-091839

Bannoehr, J., Ben Zakour, N. L., Reglinski, M., Inglis, N. F., Prabhakaran, S., Fossum, E., et al. (2011). Genomic and surface proteomic analysis of the canine pathogen Staphylococcus pseudintermedius reveals proteins that mediate adherence to the extracellular matrix. Infect. Immun. 79, 3074-3086. doi: 10.1128/IAI.00137-11

Berk, V., Fong, J. C., Dempsey, G. T., Develioglu, O. N., Zhuang, X., Liphardt, J., et al. (2012). Molecular architecture and assembly principles of Vibrio cholerae biofilms. Science 337, 236-239. doi: 10.1126/science.1222981

Beroz, F., Yan, J., Meir, Y., Sabass, B., Stone, H. A., Bassler, B. L., et al. (2018). Verticalization of bacterial biofilms. Nat. Phys. 14, 954-960. doi: 10.1038/ s41567-018-0170-4

Binnig, G., Quate, C. F., and Gerber, C. (1986). Atomic force microscope. Phys. Rev. Lett. 56, 930-933. doi: 10.1103/PhysRevLett.56.930

Bjarnsholt, T., Kirketerp-Møller, K., Jensen, P. Ø., Madsen, K. G., Phipps, R., Krogfelt, K., et al. (2008). Why chronic wounds will not heal: a novel hypothesis. Wound Repair Regen. 16, 2-10. doi: 10.1111/j.1524-475X.2007.00283.x

Blanchard, B., Imberty, A., and Varrot, A. (2014). Secondary sugar binding site identified for LecA lectin from Pseudomonas aeruginosa. Proteins 82, 1060-1065. doi: 10.1002/prot.24430

Boks, N. P., Busscher, H. J., van der Mei, H. C., and Norde, W. (2008). Bondstrengthening in staphylococcal adhesion to hydrophilic and hydrophobic surfaces using atomic force microscopy. Langmuir 24, 12990-12994. doi: $10.1021 / \mathrm{la} 801824 \mathrm{c}$

Borlee, B. R., Goldman, A. D., Murakami, K., Samudrala, R., Wozniak, D. J., and Parsek, M. R. (2010). Pseudomonas aeruginosa uses a cyclic-di-GMPregulated adhesin to reinforce the biofilm extracellular matrix. Mol. Microbiol. 75, 827-842. doi: 10.1111/j.1365-2958.2009.06991.x

Bos, R., van der Mei, H. C., and Busscher, H. J. (1999). Physico-chemistry of initial microbial adhesive interactions-its mechanisms and methods for study. FEMS Microbiol. Rev. 23, 179-230. doi: 10.1016/S0168-6445(99)00004-2

Boudarel, H., Mathias, J. D., Blaysat, B., and Grediac, M. (2018). Towards standardized mechanical characterization of microbial biofilms: analysis and critical review. npj Biofilms Microbiomes 4:17. doi: 10.1038/s41522-018-0062-5

Brandenburg, K. S., Weaver, A. J., Karna, S. L. R., You, T., Chen, P., Stryk, S. V., et al. (2019). Formation of Pseudomonas aeruginosa biofilms in full-thickness scald burn wounds in rats. Sci. Rep. 9:13627. doi: 10.1038/s41598-019-50003-8

Burrows, L. L. (2012). Pseudomonas aeruginosa twitching motility: type IV pili in action. Annu. Rev. Microbiol. 66, 493-520. doi: 10.1146/annurevmicro-092611-150055
All authors contributed to the article and approved the submitted version.

\section{FUNDING}

SM acknowledges support from the National Institutes of Health, grant no. 5K99GM129424. JY holds a Career Award at the Scientific Interface from the Burroughs Welcome Fund.

Byrd, M. S., Pang, B., Mishra, M., Swords, W. E., and Wozniak, D. J. (2010). The Pseudomonas aeruginosa exopolysaccharide Psl facilitates surface adherence and NF-kappaB activation in A549 cells. mBio 1:e00140-10. doi: 10.1128/ mBio.00140-10

Byrd, M. S., Sadovskaya, I., Vinogradov, E., Lu, H., Sprinkle, A. B., Richardson, S. H., et al. (2009). Genetic and biochemical analyses of the Pseudomonas aeruginosa Psl exopolysaccharide reveal overlapping roles for polysaccharide synthesis enzymes in Psl and LPS production. Mol. Microbiol. 73, 622-638. doi: 10.1111/j.1365-2958.2009.06795.x

Campisano, A., Schroeder, C., Schemionek, M., Overhage, J., and Rehm, B. H. (2006). PslD is a secreted protein required for biofilm formation by Pseudomonas aeruginosa. Appl. Environ. Microbiol. 72, 3066-3068. doi: 10.1128/ AEM.72.4.3066-3068.2006

Carniello, V., Peterson, B. W., van der Mei, H. C., and Busscher, H. J. (2018) Physico-chemistry from initial bacterial adhesion to surface-programmed biofilm growth. Adv. Colloid Interf. Sci. 261, 1-14. doi: 10.1016/j.cis.2018.10.005

Charles, R. C., and Ryan, E. T. (2011). Cholera in the 21st century. Curr. Opin. Infect. Dis. 24, 472-477. doi: 10.1097/QCO.0b013e32834a88af

Chen, P., Abercrombie, J. J., Jeffrey, N. R., and Leung, K. P. (2012). An improved medium for growing Staphylococcus aureus biofilm. J. Microbiol. Methods 90, 115-118. doi: 10.1016/j.mimet.2012.04.009

Cheng, Y., Grigorieff, N., Penczek, P. A., and Walz, T. (2015). A primer to single-particle cryo-electron microscopy. Cell 161, 438-449. doi: 10.1016/j. cell.2015.03.050

Chen, M. J., Zhang, Z., and Bott, T. R. (1998). Direct measurement of the adhesive strength of biofilms in pipes by micromanipulation. Biotechnol. Tech. 12, 875-880. doi: 10.1023/A:1008805326385

Chew, S. C., Kundukad, B., Seviour, T., van der Maarel, J. R. C., Yang, L., Rice, S. A., et al. (2015). Dynamic remodeling of microbial biofilms by functionally distinct exopolysaccharides. mBio 6:e01536-14. doi: 10.1128/ mBio.01536-14

Chiang, P., and Burrows, L. L. (2003). Biofilm formation by hyperpiliated mutants of Pseudomonas aeruginosa. J. Bacteriol. 185, 2374-2378. doi: 10.1128/ JB.185.7.2374-2378.2003

Clarke, S. R., and Foster, S. J. (2006). Surface adhesins of Staphylococcus aureus. Adv. Microb. Physiol. 51, 187-224. doi: 10.1016/S0065-2911(06)51004-5

Colvin, K. M., Irie, Y., Tart, C. S., Urbano, R., Whitney, J. C., Ryder, C., et al. (2012). The Pel and Psl polysaccharides provide Pseudomonas aeruginosa structural redundancy within the biofilm matrix. Environ. Microbiol. 14, 1913-1928. doi: 10.1111/j.1462-2920.2011.02657.x

Colwell, R. R., Huq, A., Islam, M. S., Aziz, K. M. A., Yunus, M., Khan, N. H., et al. (2003). Reduction of cholera in Bangladeshi villages by simple filtration. Proc. Natl. Acad. Sci. U. S. A. 100, 1051-1055. doi: 10.1073/pnas. 0237386100

Comolli, J. C., Waite, L. L., Mostov, K. E., and Engel, J. N. (1999). Pili binding to asialo-GM1 on epithelial cells can mediate cytotoxicity or bacteria internalization by Pseudomonas aeruginosa. Infect. Immun. 67, 3207-3214. doi: 10.1128/IAI.67.7.3207-3214.1999

Conlon, B. P., Geoghegan, J. A., Waters, E. M., McCarthy, H., Rowe, S. E., Davies, J. R., et al. (2014). Role for the A domain of unprocessed accumulationassociated protein (Aap) in the attachment phase of the Staphylococcus epidermidis biofilm phenotype. J. Bacteriol. 196, 4268-4275. doi: 10.1128/ JB.01946-14

Conrady, D. G., Wilson, J. J., and Herr, A. B. (2013). Structural basis for $\mathrm{Zn}^{2+}$-dependent intercellular adhesion in staphylococcal biofilms. Proc. Natl. Acad. Sci. U. S. A. 110, E202-E211. doi: 10.1073/pnas. 1208134110 
Cooley, R. B., Smith, T. J., Leung, W., Tierney, V., Borlee, B. R., O’Toole, G. A., et al. (2016). Cyclic di-GMP-regulated periplasmic proteolysis of a Pseudomonas aeruginosa type $\mathrm{Vb}$ secretion system substrate. J. Bacteriol. 198, 66-76. doi: 10.1128/JB.00369-15

Cooley, B. J., Thatcher, T. W., Hashmi, S. M., L'Her, G., Le, H. H., Hurwitz, D. A., et al. (2013). The extracellular polysaccharide Pel makes the attachment of P. aeruginosa to surfaces symmetric and short-ranged. Soft Matter 9, 3871-3876. doi: $10.1039 / \mathrm{c} 3 \mathrm{sm} 27638 \mathrm{~d}$

Corrigan, R. M., Rigby, D., Handley, P., and Foster, T. J. (2007). The role of Staphylococcus aureus surface protein SasG in adherence and biofilm formation. Microbiology 153, 2435-2446. doi: 10.1099/mic.0.2007/006676-0

Cucarella, C., Solano, C., Valle, J., Amorena, B., Lasa, I., and Penades, J. R. (2001). Bap, a Staphylococcus aureus surface protein involved in biofilm formation. J. Bacteriol. 183, 2888-2896. doi: 10.1128/JB.183.9.2888-2896.2001

Cucarella, C., Tormo, M. Á., Úbeda, C., Trotonda, M. P., Monzón, M., Peris, C., et al. (2004). Role of biofilm-associated protein bap in the pathogenesis of bovine Staphylococcus aureus. Infect. Immun. 72, 2177-2185. doi: 10.1128/ IAI.72.4.2177-2185.2004

Das, T., Sehar, S., Koop, L., Wong, Y. K., Ahmed, S., Siddiqui, K. S., et al. (2014). Influence of calcium in extracellular DNA mediated bacterial aggregation and biofilm formation. PLoS One 9:e91935. doi: 10.1371/journal.pone.0114014

de Vos, W. M. (2015). Microbial biofilms and the human intestinal microbiome. npj Biofilms Microbiomes 1:15005. doi: 10.1038/npjbiofilms.2015.5

De, S., Kaus, K., Sinclair, S., Case, B. C., and Olson, R. (2018). Structural basis of mammalian glycan targeting by Vibrio cholerae cytolysin and biofilm proteins. PLoS Pathog. 14:e1006841. doi: 10.1371/journal.ppat.1006841

De, S., and Olson, R. (2011). Crystal structure of the Vibrio cholerae cytolysin heptamer reveals common features among disparate pore-forming toxins. Proc. Natl. Acad. Sci. U. S. A. 108, 7385-7390. doi: 10.1073/pnas.1017442108

de la Fuente-Núñez, C., Reffuveille, F., Fernández, L., and Hancock, R. E. (2013). Bacterial biofilm development as a multicellular adaptation: antibiotic resistance and new therapeutic strategies. Curr. Opin. Microbiol. 16, 580-589. doi: 10.1016/j.mib.2013.06.013

Dragoš, A., and Kovács, Á. T. (2017). The peculiar functions of the bacterial extracellular matrix. Trends Microbiol. 25, 257-266. doi: 10.1016/j. tim.2016.12.010

Drescher, K., Dunkel, J., Nadell, C. D., van Teeffelen, S., Grnja, I., Wingreen, N. S., et al. (2016). Architectural transitions in Vibrio cholerae biofilms at singlecell resolution. Proc. Natl. Acad. Sci. U. S. A. 113, E2066-E2072. doi: 10.1073/ pnas. 1601702113

Dufrene, Y. F. (2002). Atomic force microscopy, a powerful tool in microbiology. J. Bacteriol. 184, 5205-5213. doi: 10.1128/JB.184.19.5205-5213.2002

Edwards, A. M., Potts, J. R., Josefsson, E., and Massey, R. C. (2010). Staphylococcus aureus host cell invasion and virulence in sepsis is facilitated by the multiple repeats within FnBPA. PLoS Pathog. 6:e1000964. doi: 10.1371/journal.ppat. 1000964

Erlendsson, S., and Teilum, K. (2021). Binding revisited-avidity in cellular function and signaling. Front. Mol. Biosci. 7:615565. doi: 10.3389/ fmolb.2020.615565

Fang, H. H., Chan, K.-Y., and Xu, L.-C. (2000). Quantification of bacterial adhesion forces using atomic force microscopy (AFM). J. Microbiol. Methods 40, 89-97. doi: 10.1016/S0167-7012(99)00137-2

Fei, C., Mao, S., Yan, J., Alert, R., Stone, H. A., Bassler, B. L., et al. (2020). Nonuniform growth and surface friction determine bacterial biofilm morphology on soft substrates. Proc. Natl. Acad. Sci. U. S. A. 117, 7622-7632. doi: $10.1073 /$ pnas. 1919607117

Flemming, H. C., Neu, T. R., and Wozniak, D. J. (2007). The EPS matrix: the "house of biofilm cells". J. Bacteriol. 189, 7945-7947. doi: 10.1128/JB.00858-07

Flemming, H. C., and Wingender, J. (2010). The biofilm matrix. Nat. Rev. Microbiol. 8, 623-633. doi: 10.1038/nrmicro2415

Fluckiger, U., Ulrich, M., Steinhuber, A., Döring, G., Mack, D., Landmann, R., et al. (2005). Biofilm formation, ica $A D B C$ transcription, and polysaccharide intercellular adhesin synthesis by staphylococci in a device-related infection model. Infect. Immun. 73, 1811-1819. doi: 10.1128/IAI.73.3.18111819.2005

Fong, J. C., Karplus, K., Schoolnik, G. K., and Yildiz, F. H. (2006). Identification and characterization of $\mathrm{RbmA}$, a novel protein required for the development of rugose colony morphology and biofilm structure in Vibrio cholerae. J. Bacteriol. 188, 1049-1059. doi: 10.1128/JB.188.3.1049-1059.2006
Fong, J. C., Rogers, A., Michael, A. K., Parsley, N. C., Cornell, W.-C., Lin, Y.-C., et al. (2017). Structural dynamics of RbmA governs plasticity of Vibrio cholerae biofilms. elife 6:e26163. doi: 10.7554/eLife.26163

Fong, J. C., Syed, K. A., Klose, K. E., and Yildiz, F. H. (2010). Role of Vibrio polysaccharide ( $v p s)$ genes in VPS production, biofilm formation and Vibrio cholerae pathogenesis. Microbiology 156, 2757-2769. doi: 10.1099/mic.0. 040196-0

Fong, J. C., and Yildiz, F. H. (2007). The rbmBCDEF gene cluster modulates development of rugose colony morphology and biofilm formation in Vibrio cholerae. J. Bacteriol. 189, 2319-2330. doi: 10.1128/JB.01569-06

Foster, T. J., Geoghegan, J. A., Ganesh, V. K., and Hook, M. (2014). Adhesion, invasion and evasion: the many functions of the surface proteins of Staphylococcus aureus. Nat. Rev. Microbiol. 12, 49-62. doi: 10.1038/nrmicro3161

Fouke, B. W. (2016). The Art of Yellowstone Science. Livingston Montana: Crystal Creek Press.

Francois, P., Schrenzel, J., Stoerman-Chopard, C., Favre, H., Herrmann, M., Foster, T. J., et al. (2000). Identification of plasma proteins adsorbed on hemodialysis tubing that promote Staphylococcus aureus adhesion. J. Lab. Clin. Med. 135, 32-42. doi: 10.1016/S0022-2143(00)70018-7

Fredrickson, J. K., Zachara, J. M., Balkwill, D. L., Kennedy, D., Li, S. M., Kostandarithes, H. M., et al. (2004). Geomicrobiology of high-level nuclear waste-contaminated vadose sediments at the Hanford site, Washington state. Appl. Environ. Microbiol. 70, 4230-4241. doi: 10.1128/AEM.70.7.4230-4241. 2004

Friedman, L., and Kolter, R. (2004). Two genetic loci produce distinct carbohydraterich structural components of the Pseudomonas aeruginosa biofilm matrix J. Bacteriol. 186, 4457-4465. doi: 10.1128/JB.186.14.4457-4465.2004

Funken, H., Bartels, K.-M., Wilhelm, S., Brocker, M., Bott, M., Bains, M., et al. (2012). Specific association of lectin LecB with the surface of Pseudomonas aeruginosa: role of outer membrane protein OprF. PLoS One 7:e46857. doi: 10.1371/journal.pone.0046857

Ganesan, M., Stewart, E. J., Szafranski, J., Satorius, A. E., Younger, J. G., and Solomon, M. J. (2013). Molar mass, entanglement, and associations of the biofilm polysaccharide of Staphylococcus epidermidis. Biomacromolecules 14, 1474-1481. doi: 10.1021/bm400149a

Geoghegan, J. A., and Dufrene, Y. F. (2018). Mechanomicrobiology: how mechanical forces activate Staphylococcus aureus adhesion. Trends Microbiol. 26, 645-648. doi: 10.1016/j.tim.2018.05.004

Geoghegan, J. A., Smith, E. J., Speziale, P., and Foster, T. J. (2009). Staphylococcus pseudintermedius expresses surface proteins that closely resemble those from Staphylococcus aureus. Vet. Microbiol. 138, 345-352. doi: 10.1016/j. vetmic.2009.03.030

Geraci, J., Neubauer, S., Pollath, C., Hansen, U., Rizzo, F., Krafft, C., et al. (2017). The Staphylococcus aureus extracellular matrix protein (Emp) has a fibrous structure and binds to different extracellular matrices. Sci. Rep. 7:13665. doi: $10.1038 / \mathrm{s} 41598-017-14168-4$

Gerber, C., and Lang, H. P. (2006). How the doors to the nanoworld were opened. Nat. Nanotechnol. 1, 3-5. doi: 10.1038/nnano.2006.70

Ghafoor, A., Hay, I. D., and Rehm, B. H. (2011). Role of exopolysaccharides in Pseudomonas aeruginosa biofilm formation and architecture. Appl. Environ. Microbiol. 77, 5238-5246. doi: 10.1128/AEM.00637-11

Giglio, K. M., Fong, J. C., Yildiz, F. H., and Sondermann, H. (2013). Structural basis for biofilm formation via the Vibrio cholerae matrix protein RbmA. J. Bacteriol. 195, 3277-3286. doi: 10.1128/JB.00374-13

Gjødsbøl, K., Christensen, J. J., Karlsmark, T., Jørgensen, B., Klein, B. M., and Krogfelt, K. A. (2006). Multiple bacterial species reside in chronic wounds: a longitudinal study. Int. Wound J. 3, 225-231. doi: 10.1111/j.1742-481X.2006.00159.x

Gloag, E. S., German, G. K., Stoodley, P., and Wozniak, D. J. (2018). Viscoelastic properties of Pseudomonas aeruginosa variant biofilms. Sci. Rep. 8:9691. doi: 10.1038/s41598-018-28009-5

Gómez, M. I., and Prince, A. (2007). Opportunistic infections in lung disease: Pseudomonas infections in cystic fibrosis. Curr. Opin. Pharmacol. 7, 244-251. doi: $10.1016 /$ j.coph.2006.12.005

Ha, D.-G., and O'Toole, G. A. (2015). c-di-GMP and its effects on biofilm formation and dispersion: a Pseudomonas aeruginosa review. Microbiol. Spectr. 3:MB-0003-2014. doi: 10.1128/microbiolspec.MB-0003-2014

Hall-Stoodley, L., Costerton, J. W., and Stoodley, P. (2004). Bacterial biofilms: from the natural environment to infectious diseases. Nat. Rev. Microbiol. 2, 95-108. doi: $10.1038 /$ nrmicro821 
Hammel, M., Nemecek, D., Keightley, J. A., Thomas, G. J., and Geisbrecht, B. V. (2007). The Staphylococcus aureus extracellular adherence protein (Eap) adopts an elongated but structured conformation in solution. Protein Sci. 16, 2605-2617. doi: 10.1110/ps.073170807

Heilmann, C. (2011). Adhesion mechanisms of staphylococci. Adv. Exp. Med. Biol. 715, 105-123. doi: 10.1007/978-94-007-0940-9_7

Heiniger, R. W., Winther-Larsen, H. C., Pickles, R. J., Koomey, M., and Wolfgang, M. C. (2010). Infection of human mucosal tissue by Pseudomonas aeruginosa requires sequential and mutually dependent virulence factors and a novel pilus-associated adhesin. Cell. Microbiol. 12, 1158-1173. doi: $10.1111 / j .1462-5822.2010 .01461 . x$

Helenius, J., Heisenberg, C. P., Gaub, H. E., and Muller, D. J. (2008). Singlecell force spectroscopy. J. Cell Sci. 121, 1785-1791. doi: 10.1242/jcs. 030999

Herman-Bausier, P., Labate, C., Towell, A. M., Derclaye, S., Geoghegan, J. A., and Dufrêne, Y. F. (2018). Staphylococcus aureus clumping factor A is a force-sensitive molecular switch that activates bacterial adhesion. Proc. Natl. Acad. Sci. U. S. A. 115, 5564-5569. doi: 10.1073/pnas.1718104115

Hollenbeck, E. C., Fong, J. C., Lim, J. Y., Yildiz, F. H., Fuller, G. G., and Cegelski, L. (2014). Molecular determinants of mechanical properties of V. cholerae biofilms at the air-liquid interface. Biophys. J. 107, 2245-2252. doi: 10.1016/j.bpj.2014.10.015

Huang, J., Liu, S., Zhang, C., Wang, X., Pu, J., Ba, F., et al. (2019). Programmable and printable Bacillus subtilis biofilms as engineered living materials. Nat. Chem. Biol. 15, 34-41. doi: 10.1038/s41589-018-0169-2

Huq, A., Whitehouse, C. A., Grim, C. J., Alam, M., and Colwell, R. R. (2008). Biofilms in water, its role and impact in human disease transmission. Curr. Opin. Biotechnol. 19, 244-247. doi: 10.1016/j.copbio.2008.04.005

Huq, A., Xu, B., Chowdhury, M. A., Islam, M. S., Montilla, R., and Colwell, R. R. (1996). A simple filtration method to remove plankton-associated Vibrio cholerae in raw water supplies in developing countries. Appl. Environ. Microbiol. 62, 2508-2512. doi: 10.1128/AEM.62.7.2508-2512.1996

Hussain, M., Herrmann, M., Eiff, C.von, Perdreau-Remington, F., and Peters, G. (1997). A 140-kilodalton extracellular protein is essential for the accumulation of Staphylococcus epidermidis strains on surfaces. Infect. Immun. 65, 519-524, doi: 10.1128/IAI.65.2.519-524.1997.

Hymes, J. P., and Klaenhammer, T. R. (2016). Stuck in the middle: fibronectinbinding proteins in gram-positive bacteria. Front. Microbiol. 7:1504. doi: 10.3389/fmicb.2016.01504

Jackson, K. D., Starkey, M., Kremer, S., Parsek, M. R., and Wozniak, D. J. (2004). Identification of $p s l$, a locus encoding a potential exopolysaccharide that is essential for Pseudomonas aeruginosa PAO1 biofilm formation. J. Bacteriol. 186, 4466-4475. doi: 10.1128/JB.186.14.4466-4475.2004

Jennings, L. K., Dreifus, J. E., Reichhardt, C., Storek, K. M., Secor, P. R., Wozniak, D. J., et al. (2021). Pseudomonas aeruginosa aggregates in cystic fibrosis sputum produce exopolysaccharides that likely impede current therapies. Cell Rep. 34:108782. doi: 10.1016/j.celrep.2021.108782

Jennings, L. K., Storek, K. M., Ledvina, H. E., Coulon, C., Marmont, L. S., Sadovskaya, I., et al. (2015). Pel is a cationic exopolysaccharide that cross-links extracellular DNA in the Pseudomonas aeruginosa biofilm matrix. Proc. Natl. Acad. Sci. U. S. A. 112, 11353-11358. doi: 10.1073/ pnas. 1503058112

Johnson, M. D., Garrett, C. K., Bond, J. E., Coggan, K. A., Wolfgang, M. C., and Redinbo, M. R. (2011). Pseudomonas aeruginosa PilY1 binds integrin in an RGD- and calcium-dependent manner. PLoS One 6:e29629. doi: 10.1371/ journal.pone.0029629

Jones, C. J., and Wozniak, D. J. (2017). Psl produced by mucoid Pseudomonas aeruginosa contributes to the establishment of biofilms and immune evasion. mBio 8:e00864-17. doi: 10.1128/mBio.00864-17

Juge, N. (2012). Microbial adhesins to gastrointestinal mucus. Trends Microbiol. 20, 30-39. doi: 10.1016/j.tim.2011.10.001

Kaus, K., Biester, A., Chupp, E., Lu, J., Visudharomn, C., and Olson, R. (2019). The $1.9 \AA$ crystal structure of the extracellular matrix protein Bap1 from Vibrio cholerae provides insights into bacterial biofilm adhesion. J. Biol. Chem. 294, 14499-14511. doi: 10.1074/jbc.RA119.008335

Kevin Kim, M., Drescher, K., Shun Pak, O., Bassler, B. L., and Stone, H. A. (2014). Filaments in curved streamlines: rapid formation of Staphylococcus aureus biofilm streamers. New J. Phys. 16:065024. doi: 10.1088/1367-2630/ $16 / 6 / 065024$
Kierek, K., and Watnick, P. I. (2003). The Vibrio cholerae O139 O-antigen polysaccharide is essential for $\mathrm{Ca}^{2+}$-dependent biofilm development in sea water. Proc. Natl. Acad. Sci. U. S. A. 100, 14357-14362. doi: 10.1073/pnas. 2334614100

Kirn, T. J., Jude, B. A., and Taylor, R. K. (2005). A colonization factor links Vibrio cholerae environmental survival and human infection. Nature 438, 863-866. doi: 10.1038/nature04249

Klausen, M., Heydorn, A., Ragas, P., Lambertsen, L., Aaes-Jørgensen, A., Molin, S., et al. (2003). Biofilm formation by Pseudomonas aeruginosa wild type, flagella and type IV pili mutants. Mol. Microbiol. 48, 1511-1524. doi: 10.1046/j.1365-2958.2003.03525.x

Kuchma, S. L., Ballok, A. E., Merritt, J. H., Hammond, J. H., Lu, W., Rabinowitz, J. D., et al. (2010). Cyclic-di-GMP-mediated repression of swarming motility by Pseudomonas aeruginosa: the pilY1 gene and its impact on surface-associated behaviors. J. Bacteriol. 192, 2950-2964. doi: 10.1128/ JB.01642-09

Lasa, I., and Penadés, J. R. (2006). Bap: a family of surface proteins involved in biofilm formation. Res. Microbiol. 157, 99-107. doi: 10.1016/j.resmic. 2005.11.003

Laventie, B.-J., Sangermani, M., Estermann, F., Manfredi, P., Planes, R., Hug, I., et al. (2019). A surface-induced asymmetric program promotes tissue colonization by Pseudomonas aeruginosa. Cell Host Microbe 25, 140-152. doi: 10.1016/j.chom.2018.11.008

Lawrence, J. R., Korber, D. R., Hoyle, B. D., Costerton, J. W., and Caldwell, D. E. (1991). Optical sectioning of microbial biofilms. J. Bacteriol. 173, 6558-6567. doi: 10.1128/JB.173.20.6558-6567.1991

Le Trong, I., Aprikian, P., Kidd, B. A., Forero-Shelton, M., Tchesnokova, V., Rajagopal, P., et al. (2010). Structural basis for mechanical force regulation of the adhesin FimH via finger trap-like $\beta$ sheet twisting. Cell 141, 645-655. doi: 10.1016/j.cell.2010.03.038

Lecuyer, S., Rusconi, R., Shen, Y., Forsyth, A., Vlamakis, H., Kolter, R., et al. (2011). Shear stress increases the residence time of adhesion of Pseudomonas aeruginosa. Biophys. J. 100, 341-350. doi: 10.1016/j. bpj.2010.11.078

Levering, V., Cao, C., Shivapooja, P., Levinson, H., Zhao, X., and Lopez, G. P. (2016). Urinary catheter capable of repeated on-demand removal of infectious biofilms via active deformation. Biomaterials 77, 77-86. doi: 10.1016/j. biomaterials.2015.10.070

Levering, V., Wang, Q., Shivapooja, P., Zhao, X., and López, G. P. (2014). Soft robotic concepts in catheter design: an on-demand fouling-release urinary catheter. Adv. Healthc. Mater. 3, 1588-1596. doi: 10.1002/ adhm.201400035

Limoli, D. H., Warren, E. A., Yarrington, K. D., Donegan, N. P., Cheung, A. L., and O'Toole, G. A. (2019). Interspecies interactions induce exploratory motility in Pseudomonas aeruginosa. elife 8:e47365. doi: 10.7554/ eLife. 47365

Liu, Q., Ponnuraj, K., Xu, Y., Ganesh, V. K., Sillanpää, J., Murray, B. E., et al. (2007). The Enterococcus faecalis MSCRAMM ACE binds its ligand by the Collagen Hug model. J. Biol. Chem. 282, 19629-19637. doi: 10.1074/jbc. M611137200

Loris, R., Tielker, D., Jaeger, K.-E., and Wyns, L. (2003). Structural basis of carbohydrate recognition by the lectin LecB from Pseudomonas aeruginosa. J. Mol. Biol. 331, 861-870. doi: 10.1016/S0022-2836(03)00754-X

Luo, M., Zhang, X., Zhang, S., Zhang, H., Yang, W., Zhu, Z., et al. (2017). Crystal structure of an invasivity-associated domain of $\mathrm{SdrE}$ in $S$. aureus. PLoS One 12:e0168814. doi: 10.1371/journal.pone.0168814

Luo, Y., Zhao, K., Baker, A. E., Kuchma, S. L., Coggan, K. A., Wolfgang, M. C., et al. (2015). A hierarchical cascade of second messengers regulates Pseudomonas aeruginosa surface behaviors. mBio 6:e2456-14. doi: 10.1128/mBio. 02456-14

Lyczak, J. B., Cannon, C. L., and Pier, G. B. (2002). Lung infections associated with cystic fibrosis. Clin. Microbiol. Rev. 15, 194-222. doi: 10.1128/ CMR.15.2.194-222.2002

Ma, L., Conover, M., Lu, H., Parsek, M. R., Bayles, K., and Wozniak, D. J. (2009). Assembly and development of the Pseudomonas aeruginosa biofilm matrix. PLoS Pathog. 5:e1000354. doi: 10.1371/journal.ppat.1000354

Ma, L., Jackson, K. D., Landry, R. M., Parsek, M. R., and Wozniak, D. J. (2006). Analysis of Pseudomonas aeruginosa conditional psl variants reveals roles for the psl polysaccharide in adhesion and maintaining biofilm 
structure postattachment. J. Bacteriol. 188, 8213-8221. doi: 10.1128/JB. 01202-06

Maestre-Reyna, M., Wu, W.-J., and Wang, A. H.-J. (2013). Structural insights into RbmA, a biofilm scaffolding protein of $V$. cholerae. PLoS One 8:e82458. doi: 10.1371/journal.pone.0082458

Mark Welch, J. L., Rossetti, B. J., Rieken, C. W., Dewhirst, F. E., and Borisy, G. G. (2016). Biogeography of a human oral microbiome at the micron scale. Proc. Natl. Acad. Sci. U. S. A. 113, E791-E800. doi: 10.1073/pnas.1522149113

Marth, J. D., and Grewal, P. K. (2008). Mammalian glycosylation in immunity. Nat. Rev. Immunol. 8, 874-887. doi: 10.1038/nri2417

Massey, R. C., Kantzanou, M. N., Fowler, T., Day, N. P., Schofield, K., Wann, E. R., et al. (2001). Fibronectin-binding protein A of Staphylococcus aureus has multiple, substituting, binding regions that mediate adherence to fibronectin and invasion of endothelial cells. Cell. Microbiol. 3, 839-851. doi: 10.1046/j. 1462-5822.2001.00157.x

Mazmanian, S. K., Liu, G., Ton-That, H., and Schneewind, O. (1999). Staphylococcus aureus sortase, an enzyme that anchors surface proteins to the cell wall. Science 285, 760-763. doi: 10.1126/science.285.5428.760

Meibom, K. L., Li, X. B., Nielsen, A. T., Wu, C.-Y., Roseman, S., and Schoolnik, G. K. (2004). The Vibrio cholerae chitin utilization program. Proc. Natl. Acad. Sci. U. S. A. 101, 2524-2529. doi: 10.1073/pnas. 0308707101

Miller, C. J., Drasar, B. S., and Feachem, R. G. (1984). Response of toxigenic Vibrio cholerae 01 to physico-chemical stresses in aquatic environments. Epidemiol. Infect. 93, 475-495. doi: 10.1017/s0022172400065074

Milles, L. F., Schulten, K., Gaub, H. E., and Bernardi, R. C. (2018). Molecular mechanism of extreme mechanostability in a pathogen adhesin. Science 359, 1527-1533. doi: 10.1126/science.aar2094

Mitchell, E., Houles, C., Sudakevitz, D., Wimmerova, M., Gautier, C., Pérez, S., et al. (2002). Structural basis for oligosaccharide-mediated adhesion of Pseudomonas aeruginosa in the lungs of cystic fibrosis patients. Nat. Struct. Biol. 9, 918-921. doi: 10.1038/nsb865

Mitchell, E. P., Sabin, C., Šnajdrová, L., Pokorná, M., Perret, S., Gautier, C., et al. (2005). High affinity fucose binding of Pseudomonas aeruginosa lectin PA-IIL: $1.0 \AA$ resolution crystal structure of the complex combined with thermodynamics and computational chemistry approaches. Proteins 58, 735-746. doi: 10.1002/prot.20330

Moreau-Marquis, S., Stanton, B. A., and O’Toole, G. A. (2008). Pseudomonas aeruginosa biofilm formation in the cystic fibrosis airway. Pulm. Pharmacol. Ther. 21, 595-599. doi: 10.1016/j.pupt.2007.12.001

Moremen, K. W., Tiemeyer, M., and Nairn, A. V. (2012). Vertebrate protein glycosylation: diversity, synthesis and function. Nat. Rev. Mol. Cell Biol. 13, 448-462. doi: 10.1038/nrm3383

Morris, J. G. Jr., Sztein, M. B., Rice, E. W., Nataro, J. P., Losonsky, G. A., Panigrahi, P., et al. (1996). Vibrio cholerae O1 can assume a chlorine-resistant rugose survival form that is virulent for humans. J. Infect. Dis. 174, 1364-1368. doi: $10.1093 /$ infdis/174.6.1364

Müller, J., Miller, M. C., Nielsen, A. T., Schoolnik, G. K., and Spormann, A. M. (2007). vpsA- and luxO-independent biofilms of Vibrio cholerae. FEMS Microbiol. Lett. 275, 199-206. doi: 10.1111/j.1574-6968.2007.00884.x

Nelson, E. J., Harris, J. B., Morris, J. G., Calderwood, S. B., and Camilli, A. (2009). Cholera transmission: the host, pathogen and bacteriophage dynamic. Nat. Rev. Microbiol. 7, 693-702. doi: 10.1038/nrmicro2204

O’Neill, E., Pozzi, C., Houston, P., Humphreys, H., Robinson, D. A., Loughman, A., et al. (2008). A novel Staphylococcus aureus biofilm phenotype mediated by the fibronectin-binding proteins, FnBPA and FnBPB. J. Bacteriol. 190, 3835-3850. doi: 10.1128/JB.00167-08

O’Toole, G. A., and Kolter, R. (1998). Flagellar and twitching motility are necessary for Pseudomonas aeruginosa biofilm development. Mol. Microbiol. 30, 295-304. doi: 10.1046/j.1365-2958.1998.01062.x

O’Toole, G. A., and Wong, G. C. (2016). Sensational biofilms: surface sensing in bacteria. Curr. Opin. Microbiol. 30, 139-146. doi: 10.1016/j.mib.2016.02.004

Ohashi, A., and Harada, H. (1994). Adhesion strength of biofilm developed in an attached-growth reactor. Water Sci. Technol. 29, 281-288. doi: 10.2166/ wst. 1994.0771

Otto, M. (2008). Staphylococcal biofilms. Curr. Opin. Microbiol. Immunol. 322, 207-228. doi: 10.1128/microbiolspec.GPP3-0023-2018

Overhage, J., Schemionek, M., Webb, J. S., and Rehm, B. H. (2005). Expression of the psl operon in Pseudomonas aeruginosa PAO1 biofilms: PslA performs an essential function in biofilm formation. Appl. Environ. Microbiol. 71, 4407-4413. doi: 10.1128/AEM.71.8.4407-4413.2005

Parastan, R., Kargar, M., Solhjoo, K., and Kafilzadeh, F. (2020). A synergistic association between adhesion-related genes and multidrug resistance patterns of Staphylococcus aureus isolates from different patients and healthy individuals. J. Glob. 22, 379-385. doi: 10.1016/j.jgar.2020.02.025

Passos da Silva, D., Matwichuk, M. L., Townsend, D. O., Reichhardt, C., Lamba, D., Wozniak, D. J., et al. (2019). The Pseudomonas aeruginosa lectin LecB binds to the exopolysaccharide Psl and stabilizes the biofilm matrix. Nat. Commun. 10:2183. doi: 10.1038/s41467-019-10201-4

Ponnuraj, K., Bowden, M. G., Davis, S., Gurusiddappa, S., Moore, D., Choe, D., et al. (2003). A "dock, lock, and latch" structural model for a staphylococcal adhesin binding to fibrinogen. Cell 115, 217-228. doi: 10.1016/ S0092-8674(03)00809-2

Ponnuraj, K., and Narayana, S. V. (2007). Crystal structure of ACE19, the collagen binding subdomain of Enterococus faecalis surface protein ACE. Proteins 69, 199-203. doi: 10.1002/prot.21464

Poole, P. (2017). Shining a light on the dark world of plant root-microbe interactions. Proc. Natl. Acad. Sci. U. S. A. 114, 4281-4283. doi: 10.1073/ pnas. 1703800114

Powell, L. C., Pritchard, M. F., Ferguson, E. L., Powell, K. A., Patel, S. U., Rye, P. D., et al. (2018). Targeted disruption of the extracellular polymeric network of Pseudomonas aeruginosa biofilms by alginate oligosaccharides. npj Biofilms Microbiomes 4:13. doi: 10.1038/s41522-018-0056-3

Prystopiuk, V., Feuillie, C., Herman-Bausier, P., Viela, F., Alsteens, D., Pietrocola, G., et al. (2018). Mechanical forces guiding Staphylococcus aureus cellular invasion. ACS Nano 12, 3609-3622. doi: 10.1021/acsnano.8b00716

Purdy, A. E., and Watnick, P. I. (2011). Spatially selective colonization of the arthropod intestine through activation of Vibrio cholerae biofilm formation. Proc. Natl. Acad. Sci. U. S. A. 108, 19737-19742. doi: 10.1073/pnas.1111530108

Reguera, G., and Kolter, R. (2005). Virulence and the environment: a novel role for Vibrio cholerae toxin-coregulated pili in biofilm formation on chitin. J. Bacteriol. 187, 3551-3555. doi: 10.1128/JB.187.10.3551-3555.2005

Reichhardt, C., Fong, J. C., Yildiz, F., and Cegelski, L. (2015). Characterization of the Vibrio cholerae extracellular matrix: a top-down solid-state NMR approach. Biochim. Biophys. Acta Biomembr. 1848, 378-383. doi: 10.1016/j. bbamem.2014.05.030

Reichhardt, C., Jacobs, H. M., Matwichuk, M., Wong, C., Wozniak, D. J., and Parsek, M. R. (2020). The versatile Pseudomonas aeruginosa biofilm matrix protein CdrA promotes aggregation through different extracellular exopolysaccharide interactions. J. Bacteriol. 202:e00216-20. doi: 10.1128/ JB.00216-20

Reichhardt, C., and Parsek, M. R. (2019). Confocal laser scanning microscopy for analysis of Pseudomonas aeruginosa biofilm architecture and matrix localization. Front. Microbiol. 10:677. doi: 10.3389/fmicb.2019.00677

Reichhardt, C., Wong, C., da Silva, D. P., Wozniak, D. J., and Parsek, M. R. (2018). CdrA interactions within the Pseudomonas aeruginosa biofilm matrix safeguard it from proteolysis and promote cellular packing. mBio 9:e01376-18. doi: $10.1128 / \mathrm{mBio} .01376-18$

Rodrigue, A., Quentin, Y., Lazdunski, A., Mejean, V., and Foglino, M. (2000). Two-component systems in Pseudomonas aeruginosa: why so many? Trends Microbiol. 8, 498-504. doi: 10.1016/S0966-842X(00)01833-3

Rohde, H., Burdelski, C., Bartscht, K., Hussain, M., Buck, F., Horstkotte, M. A., et al. (2005). Induction of Staphylococcus epidermidis biofilm formation via proteolytic processing of the accumulation-associated protein by staphylococcal and host proteases. Mol. Microbiol. 55, 1883-1895. doi: 10.1111/j.1365-2958. 2005.04515.x

Rumbaugh, K. P., and Sauer, K. (2020). Biofilm dispersion. Nat. Rev. Microbiol. 18, 571-586. doi: 10.1038/s41579-020-0385-0

Rybtke, M., Berthelsen, J., Yang, L., Høiby, N., Givskov, M., and Tolker-Nielsen, T. (2015). The LapG protein plays a role in Pseudomonas aeruginosa biofilm formation by controlling the presence of the CdrA adhesin on the cell surface. Microbiology 4, 917-930. doi: 10.1002/mbo3.301

Saiman, L., Ishimoto, K., Lory, S., and Prince, A. (1990). The effect of piliation and exoproduct expression on the adherence of Pseudomonas aeruginosa to respiratory epithelial monolayers. J. Infect. Dis. 161, 541-548. doi: 10.1093/ infdis/161.3.541

Sauer, K., Camper, A. K., Ehrlich, G. D., Costerton, J. W., and Davies, D. G. (2002). Pseudomonas aeruginosa displays multiple phenotypes during 
development as a biofilm. J. Bacteriol. 184, 1140-1154. doi: 10.1128/ jb.184.4.1140-1154.2002

Schiffer, C., Hilgarth, M., Ehrmann, M., and Vogel, R. F. (2019). Bap and cell surface hydrophobicity are important factors in Staphylococcus xylosus biofilm formation. Front. Microbiol. 10:1387. doi: 10.3389/fmicb.2019.01387

Schniederberend, M., Williams, J. F., Shine, E., Shen, C., Jain, R., Emonet, T., et al. (2019). Modulation of flagellar rotation in surface-attached bacteria: a pathway for rapid surface-sensing after flagellar attachment. PLoS Pathog. 15:e1008149. doi: 10.1371/journal.ppat.1008149

Simm, R., Morr, M., Kader, A., Nimtz, M., and Romling, U. (2004). GGDEF and EAL domains inversely regulate cyclic di-GMP levels and transition from sessility to motility. Mol. Microbiol. 53, 1123-1134. doi: 10.1111/j. 1365-2958.2004.04206.x

Singh, P. K., Bartalomej, S., Hartmann, R., Jeckel, H., Vidakovic, L., Nadell, C. D., et al. (2017). Vibrio cholerae combines individual and collective sensing to trigger biofilm dispersal. Curr. Biol. 27, 3359-3366. doi: 10.1016/j. cub.2017.09.041

Sinha, B., François, P. P., Nüße, O., Foti, M., Hartford, O. M., Vaudaux, P., et al. (1999). Fibronectin-binding protein acts as Staphylococcus aureus invasin via fibronectin bridging to integrin $\alpha 5 \beta 1$. Cell. Microbiol. 1, 101-117. doi: 10.1046/j.1462-5822.1999.00011.x

Sinha, B., and Herrmann, M. (2005). Mechanism and consequences of invasion of endothelial cells by Staphylococcus aureus. J. Thromb. Haemost. 94, 266-277. doi: 10.1160/TH05-04-0235

Smith, D. R., Maestre-Reyna, M., Lee, G., Gerard, H., Wang, A. H., and Watnick, P. I. (2015). In situ proteolysis of the Vibrio cholerae matrix protein RbmA promotes biofilm recruitment. Proc. Natl. Acad. Sci. U. S. A. 112, 10491-10496. doi: 10.1073/pnas.1512424112

Stauder, M., Vezzulli, L., Pezzati, E., Repetto, B., and Pruzzo, C. (2010). Temperature affects Vibrio cholerae O1 El Tor persistence in the aquatic environment via an enhanced expression of GbpA and MSHA adhesins. Environ. Microbiol. Rep. 2, 140-144. doi: 10.1111/j.1758-2229.2009. 00121.x

Stewart, P. S., and Costerton, J. W. (2001). Antibiotic resistance of bacteria in biofilms. Lancet 358, 135-138. doi: 10.1016/S0140-6736(01)05321-1

Stewart, E. J., Ganesan, M., Younger, J. G., and Solomon, M. J. (2015). Artificial biofilms establish the role of matrix interactions in staphylococcal biofilm assembly and disassembly. Sci. Rep. 5:13081. doi: 10.1038/srep13081

Taglialegna, A., Navarro, S., Ventura, S., Garnett, J. A., Matthews, S., Penades, J. R., et al. (2016). Staphylococcal bap proteins build amyloid scaffold biofilm matrices in response to environmental signals. PLoS Pathog. 12:e1005711. doi: 10.1371/journal.ppat.1005711

Tamayo, R., Patimalla, B., and Camilli, A. (2010). Growth in a biofilm induces a hyperinfectious phenotype in Vibrio cholerae. Infect. Immun. 78, 3560-3569. doi: $10.1128 /$ IAI.00048-10

Tarn, J., Peoples, L. M., Hardy, K., Cameron, J., and Bartlett, D. H. (2016). Identification of free-living and particle-associated microbial communities present in hadal regions of the Mariana Trench. Front. Microbiol. 7:665. doi: $10.3389 /$ fmicb.2016.00665

Taylor, R. K., Miller, V. L., Furlong, D. B., and Mekalanos, J. J. (1987). Use of phoA gene fusions to identify a pilus colonization factor coordinately regulated with cholera toxin. Proc. Natl. Acad. Sci. U. S. A. 84, 2833-2837. doi: $10.1073 /$ pnas.84.9.2833

Teschler, J. K., Zamorano-Sánchez, D., Utada, A. S., Warner, C. J. A., Wong, G. C. L., Linington, R. G., et al. (2015). Living in the matrix: assembly and control of Vibrio cholerae biofilms. Nat. Rev. Microbiol. 13, 255-268. doi: 10.1038/ nrmicro3433

Thewes, N., Loskill, P., Jung, P., Peisker, H., Bischoff, M., Herrmann, M., et al. (2014). Hydrophobic interaction governs unspecific adhesion of staphylococci: a single cell force spectroscopy study. Beilstein J. Nanotechnol. 5, 1501-1512. doi: 10.3762 /bjnano.5.163

Thi, M. T. T., Wibowo, D., and Rehm, B. H. A. (2020). Pseudomonas aeruginosa biofilms. Int. J. Mol. Sci. 21:8671. doi: 10.3390/ijms21228671

Tormo, M. Á., Knecht, E., Götz, F., Lasa, I., and Penadés, J. R. Y. (2005). Bap-dependent biofilm formation by pathogenic species of Staphylococcus: evidence of horizontal gene transfer? Microbiology 151, 2465-2475. doi: 10.1099/mic.0.27865-0

Visini, R., Jin, X., Bergmann, M., Michaud, G., Pertici, F., Fu, O., et al. (2015). Structural insight into multivalent galactoside binding to Pseudomonas aeruginosa lectin LecA. ACS Chem. Biol. 10, 2455-2462. doi: 10.1021/ acschembio. 5 b00302

Vitry, P., Valotteau, C., Feuillie, C., Bernard, S., Alsteens, D., Geoghegan, J. A., et al. (2017). Force-induced strengthening of the interaction between Staphylococcus aureus clumping factor B and loricrin. mBio 8:e01748-17. doi: 10.1128/mBio.01748-17

Vorkapic, D., Mitterer, F., Pressler, K., Leitner, D. R., Anonsen, J. H., Liesinger, L., et al. (2019). A broad spectrum protein glycosylation system influences type II protein secretion and associated phenotypes in Vibrio cholerae. Front. Microbiol. 10:2780. doi: 10.3389/fmicb.2019.02780

Vuong, C., Kocianova, S., Voyich, J. M., Yao, Y., Fischer, E. R., DeLeo, F. R., et al. (2004). A crucial role for exopolysaccharide modification in bacterial biofilm formation, immune evasion, and virulence. J. Biol. Chem. 279, 54881-54886. doi: 10.1074/jbc.M411374200

Wai, S. N., Mizunoe, Y., Takade, A., Kawabata, S.-I., and Yoshida, S.-I. (1998). Vibrio cholerae O1 strain TSI-4 produces the exopolysaccharide materials that determine colony morphology, stress resistance, and biofilm formation. Appl. Environ. Microbiol. 64, 3648-3655. doi: 10.1128/AEM.64.10. 3648-3655.1998

Wang, S., Liu, X., Liu, H., Zhang, L., Guo, Y., Yu, S., et al. (2015). The exopolysaccharide Psl-eDNA interaction enables the formation of a biofilm skeleton in Pseudomonas aeruginosa. Environ. Microbiol. Rep. 7, 330-340. doi: $10.1111 / 1758-2229.12252$

Watnick, P. I., Fullner, K. J., and Kolter, R. (1999). A role for the mannosesensitive hemagglutinin in biofilm formation by Vibrio cholerae El Tor. J. Bacteriol. 181, 3606-3609. doi: 10.1128/JB.181.11.3606-3609.1999

Whitchurch, C. B., Tolker-Nielsen, T., Ragas, P. C., and Mattick, J. S. (2002). Extracellular DNA required for bacterial biofilm formation. Science 295:1487. doi: $10.1126 /$ science.295.5559.1487

Wloka, M., Rehage, H., Flemming, H.-C., and Wingender, J. (2004). Rheological properties of viscoelastic biofilm extracellular polymeric substances and comparison to the behavior of calcium alginate gels. Colloid Polym. Sci. 282, 1067-1076. doi: 10.1007/s00396-003-1033-8

Wuertz, S., Bishop, P. L., and Wilderer, P. A. (2003). Biofilms in Wastewater Treatment. London: IWA Publishing.

Yamamoto, T., Nishiyama, A., Takano, T., Yabe, S., Higuchi, W., Razvina, O. et al. (2010). Community-acquired methicillin-resistant Staphylococcus aureus: community transmission, pathogenesis, and drug resistance. J. Infect. Chemother. 16, 225-254. doi: 10.1007/s10156-010-0045-9

Yan, J., and Bassler, B. L. (2019). Surviving as a community: antibiotic tolerance and persistence in bacterial biofilms. Cell Host Microbe 26, 15-21. doi: 10.1016/j.chom.2019.06.002

Yan, J., Fei, C., Mao, S., Moreau, A., Wingreen, N. S., Košmrlj, A., et al. (2019). Mechanical instability and interfacial energy drive biofilm morphogenesis. elife 8:e43920. doi: 10.7554/eLife.43920

Yan, J., Moreau, A., Khodaparast, S., Perazzo, A., Feng, J., Fei, C., et al. (2018). Bacterial biofilm material properties enable removal and transfer by capillary peeling. $A d v$. Mater. 30:e1804153. doi: 10.1002/adma. 201804153

Yan, J., Nadell, C. D., and Bassler, B. L. (2017). Environmental fluctuation governs selection for plasticity in biofilm production. ISME J. 11, 1569-1577. doi: $10.1038 /$ ismej.2017.33

Yan, J., Sharo, A. G., Stone, H. A., Wingreen, N. S., and Bassler, B. L. (2016). Vibrio cholerae biofilm growth program and architecture revealed by singlecell live imaging. Proc. Natl. Acad. Sci. U. S. A. 113, e5337-e5343. doi: 10.1073/pnas.1611494113

Yarawsky, A. E., Johns, S. L., Schuck, P., and Herr, A. B. (2020). The biofilm adhesion protein Aap from Staphylococcus epidermidis forms zinc-dependent amyloid fibers. J. Biol. Chem. 295, 4411-4427. doi: 10.1074/jbc.RA119. 010874

Yildiz, F., Fong, J., Sadovskaya, I., Grard, T., and Vinogradov, E. (2014). Structural characterization of the extracellular polysaccharide from Vibrio cholerae $\mathrm{O} 1$ El-Tor. PLoS One 9:e86751. doi: 10.1371/journal.pone.0086751

Yildiz, F. H., and Schoolnik, G. K. (1999). Vibrio cholerae O1 El Tor: identification of a gene cluster required for the rugose colony type, exopolysaccharide production, chlorine resistance, and biofilm formation. Proc. Natl. Acad. Sci. U. S. A. 96, 4028-4033. doi: 10.1073/pnas.96.7.4028

Zhang, Y., Wu, M., Hang, T., Wang, C., Yang, Y., Pan, W., et al. (2017). Staphylococcus aureus SdrE captures complement factor H's C-terminus via 
a novel "close, dock, lock and latch" mechanism for complement evasion. Biochem. J. 474, 1619-1631. doi: 10.1042/BCJ20170085

Zhao, K., Tseng, B. S., Beckerman, B., Jin, F., Gibiansky, M. L., Harrison, J. J., et al. (2013). Psl trails guide exploration and microcolony formation in Pseudomonas aeruginosa biofilms. Nature 497, 388-391. doi: 10.1038/ nature 12155

Zoutman, D. E., Hulbert, W. C., Pasloske, B. L., Joffe, A. M., Volpel, K., Trebilcock, M. K., et al. (1991). The role of polar pili in the adherence of Pseudomonas aeruginosa to injured canine tracheal cells: a semiquantitative morphologic study. Scanning Microsc. 5, 109-124.
Conflict of Interest: The authors declare that the research was conducted in the absence of any commercial or financial relationships that could be construed as a potential conflict of interest.

Copyright (c) 2021 Jiang, Nero, Mukherjee, Olson and Yan. This is an open-access article distributed under the terms of the Creative Commons Attribution License (CC BY). The use, distribution or reproduction in other forums is permitted, provided the original author(s) and the copyright owner(s) are credited and that the original publication in this journal is cited, in accordance with accepted academic practice. No use, distribution or reproduction is permitted which does not comply with these terms. 